\title{
A Constitutive Stress Response is an Adaptation to Low Temperature in the Antarctic green alga Chlamydomonas sp. UWO241
}

\author{
Marina Cvetkovska ${ }^{1}$, Xi Zhang ${ }^{2}$, Galyna Vakulenko ${ }^{1}$, Samuel Benzaquen ${ }^{1}$, Beth \\ Szyszka-Mroz ${ }^{2}$, Nina Malczewski², David Smith², and Norman P. A. Huner ${ }^{2}$ \\ ${ }^{1}$ University of Ottawa \\ ${ }^{2}$ University of Western Ontario
}

July 16, 2021

\begin{abstract}
The Antarctic green alga Chlamydomonas sp. UWO241 is an obligate psychrophile that thrives in the cold $\left(4-6^{\circ} \mathrm{C}\right)$ but is unable to survive at temperatures [?]18degC. Little is known how exposure to heat affects its physiology or whether it mounts a heat stress response in a manner comparable to mesophiles. Here, we dissect the responses of UWO241 to temperature stress by examining its growth, primary metabolome and transcriptome under steady-state low temperature and heat stress conditions. In comparison with Chlamydomonas reinhardtii, UWO241 constitutively accumulates metabolites and proteins commonly considered as stress markers, including soluble sugars, antioxidants, polyamines, and heat shock proteins to ensure efficient protein folding at low temperatures. We propose that this permanent stress metabolism is an adaptive advantage to life at extreme conditions. A shift from $4 \mathrm{degC}$ to a non-permissive temperature of $24 \mathrm{degC}$ alters the UWO241 primary metabolome and transcriptome, but growth of UWO241 at higher permissive temperatures (10degC and 15degC) does not provide enhanced heat protection. UWO241 also fails to induce the accumulation of HSPs when exposed to heat, suggesting that it has lost the ability to fine-tune its heat stress response. Our work adds to the growing body of research on temperature stress in psychrophiles, many of which are threatened by climate change.
\end{abstract}

\section{INTRODUCTION}

Perennially cold environments, such as polar and alpine regions, are one of the world's largest ecosystems. Phototrophic microbes, many of which are obligate cold extremophiles (psychrophiles), are the dominant primary producers in these habitats and the base of virtually all low temperature food webs (Morgan-Kiss, Priscu, Pocock, Gudynaite-Savitch \& Huner 2006; Margesin 2008; Lyon \& Mock 2014; Chrismas, Anesio \& Sánchez-Baracaldo 2015). Most studies on psychrophily focus on the biochemical characteristics that enable these organisms to thrive at permanently low temperatures, including cold-adapted proteins and increases in membrane fluidity, as well as the presence of ice-binding proteins, antifreeze proteins and cryoprotectants (reviewed in Siddiquiet al. 2013; De Maayer, Anderson, Cary \& Cowan 2014). But a distinguishing feature of psychrophiles is not an exceptional ability to grow at low temperatures. Indeed, many land plants, green algae and cyanobacteria survive and grow at both cold and warm temperatures and are therefore not psychrophilic (Huner, Öquist \& Sarhan 1998; Tang \& Vincent 1999; Öquist \& Huner 2003; Hüner et al. 2012; Yamori, Hikosaka \& Way 2014; Chang, Bräutigam, Hüner \& Ensminger 2021). Rather, it is the inability of psychrophiles to survive at moderate (mesophilic) temperatures ([?]20degC) that distinguishes them from cold-tolerant species (Morita 1975).

Chlamydomonas sp. UWO241 is one of the most comprehensively studied algal psychrophiles and an upand-coming model for photosynthetic adaptation to extreme environments (Morgan-Kiss et al. 2006; Dolhi, 
Maxwell \& Morgan-Kiss 2013; Cvetkovska, Huner \& Smith 2017). This alga resides at a depth of 17 meters within the water column of the perennially ice-covered Antarctic Lake Bonney (Neale \& Priscu 1995), where it faces several environmental challenges including constantly low temperatures ( $\sim 5 \mathrm{degC})$, high salinity $(0.7 \mathrm{M})$, extreme shading $\left(5-15 \mu \mathrm{mol} \mathrm{m} \mathrm{m}^{-2} \mathrm{~s}^{-1}\right)$, high oxygen concentrations (200\% air saturation levels), low phosphorus levels ( $\mathrm{N}: \mathrm{P}^{\sim 1000}$ ), and seasonal extremes in photoperiod. While this environment is extreme in many aspects, it is also very stable. The perennial ice-cover prevents wind-driven water mixing and promotes a vertically stratified environment where the salinity, nutrient levels and temperature profiles remain extraordinarily constant year-round (Obryk, Doran, Hicks, McKay \& Priscu 2016; Spigel, Priscu, Obryk, Stone \& Doran 2018).

In green algae, heat stress affects most cellular processes, including the fluidity of biological membranes, metabolism, enzyme activities and protein homeostasis. To maintain cellular function and prevent irreversible damage, green algae induce a heat stress response (HSR) that involves arrest of active cell growth, a switch from regular to stress metabolism, compositional remodelling of membrane lipids, and maintenance of protein homeostasis (Schroda, Hemme \& Mühlhaus 2015). One of the first responses to heat stress is the increased transcription of genes encoding Heat Shock Proteins (HSPs), highly conserved molecular chaperones that engage in nascent protein synthesis as well as folding and transport (Lindquist \& Craig 1988; Vierling 2003; Wang, Vinocur, Shoseyov \& Altman 2004; Gupta, Sharma, Mishra, Mishra \& Chowdhuri 2010). HSPs were first described in relation to heat shock inDrosophila (Ritossa 1962), but are now known to be important in both normal homeostatic growth (Lindquist \& Craig 1988) as well as during several abiotic and biotic stresses (Vierling 2003; Wang et al. 2004; Park \& Seo 2015). Their function has been extensively studied in the model green alga Chlamydomonas reinhardtii (Schroda \& Vallon 2009; Nordhues, Miller, Mühlhaus \& Schroda 2010; Schroda et al. 2015), where their expression is regulated by a single heat shock transcription factor (HSF1) (Schmollinger et al. 2013). The HSR in C. reinhardtii is rapidly initiated, with increased HSP expression seen within the first 25 minutes of exposure to $42^{\circ} \mathrm{C}$ and robustly maintained for at least 24 hours (Mühlhaus, Weiss, Hemme, Sommer \& Schroda 2011; Hemme et al. 2014; Légeretet al. 2016).

Life in the perpetual cold has shaped the physiological make-up of UWO241, which has been mostly studied at the level of its photosynthetic machinery, as reviewed in (Cvetkovska et al. 2017) and subsequently discussed in (Szyszka-Mroz et al. 2019; Cooket al. 2019; Kalra et al. 2020). This alga is unable to grow above $18^{\circ} \mathrm{C}$, but little is known how exposure to temperatures above this upper growth limit affect its physiology. It been shown that exposure to $24^{\circ} \mathrm{C}$ is lethal but cell death occurs slowly, and the effects are reversible in the first 12 hours (Possmayer et al. 2011). Short-term exposure to $24^{\circ} \mathrm{C}$ resulted in cessation of cell growth, inhibition of PSII efficiency and expression of the molecular chaperone HSP22A, and longer exposures led to cell death (Possmayer et al.2011). In addition, two key photosynthetic proteins in UWO241, ferredoxin (Cvetkovska et al. 2018) and the chloroplast kinase STT7 (Szyszka-Mroz et al. 2019) were shown to be specifically adapted to low temperatures, with higher activities in the cold but at the expense of increased sensitivity and loss of activity at more moderate temperatures when compared to their mesophilic homologs from C. reinhardtii .

While it is clear that UWO241 experiences stress at moderate temperatures, it is currently unknown whether this psychrophile mounts an HSR in a manner comparable to its mesophilic relatives. To gain insight into the systemic response of UWO241 to temperature stress, we examined the growth, primary metabolome and transcriptome of UWO241 under steady-state low temperature and heat stress conditions. The recent sequencing of the UWO241 genome (Zhang, Cvetkovska, Morgan-Kiss, Hüner \& Smith 2021a) has placed UWO241 in an excellent position for comparative sequence analysis since it is phylogenetically closely related to a number of model green algae models, including C. reinhardtii (Possmayer et al. 2016; Cvetkovska et al.2017). Using this new resource, we investigated the presence of HSP genes in the UWO241 genome and their responsiveness to heat stress using RNA-Seq and protein immunoblotting. Our work contributes to a better understanding of psychrophilic stress biology, a question that is gaining in importance since polar environments are particularly threatened by current patterns of global climate change (Xavier et al. 2016; Kennicutt et al. 2019).

\section{MATERIALS \& METHODS}




\section{Strains and Growth Conditions}

Chlamydomonas sp. UWO241 and Chlamydomonas reinhardtii(cc-1690) were grown axenically in Bold's Basal Medium (BBM) supplemented with $10 \mathrm{mM} \mathrm{NaCl}$. All cultures were aerated continuously with ambient air filtered by a $0.2 \mu \mathrm{m}$ filter in $250 \mathrm{ml}$ glass growth tubes suspended in thermo-regulated aquaria. A continuous growth irradiance of $130 \mu \mathrm{mol}$ photons $\mathrm{m}^{-2} \mathrm{~s}^{-1}$ was generated by fluorescent tubes (Sylvania CW40) and measured with a quantum sensor attached to a radiometer (Model LI-189; Li-Cor). Algal cultures were exposed to heat stress by transfer to aquaria maintained at $24^{\circ} \mathrm{C}(\mathrm{UWO} 241)$ and $42^{\circ} \mathrm{C}(\mathrm{C}$. reinhardtii ). Mid-log cultures were used in all experiments.

\section{Growth and Cell Death Kinetics}

Cell growth was estimated by measuring optical density at $750 \mathrm{~nm}\left(\mathrm{OD}_{750}\right)$ and chlorophyll concentration in algal cultures over time (Possmayer et al. 2011). The concentrations of chlorophyll $a$ and $b$ were measured spectrophotometrically at 647 and $664 \mathrm{~nm}$ (Cary 50 Bio; Varian, USA) and calculated as described (Jeffrey \& Humphrey 1975). Maximum growth rates were calculated using natural log transformation of the optical density values during the exponential phase. Culture viability was assayed by resuspending pelleted algal cells in $0.5 \%(\mathrm{w} / \mathrm{v})$ Evans Blue solution, incubating for $30 \mathrm{~min}$ and removing the unbound dye by washing with BBM medium. Dye bound to dead cells was solubilized in $50 \%(\mathrm{v} / \mathrm{v})$ methanol and $1 \%(\mathrm{w} / \mathrm{v})$ SDS, and extracted by incubation at $50^{\circ} \mathrm{C}$ for $30 \mathrm{~min}$. The suspension was centrifuged $(16,000 \mathrm{~g}, 3 \mathrm{~min})$ and absorbance was measured spectrophotometrically at $600 \mathrm{~nm}$. The absorbance of cells treated with $1 \%(\mathrm{v} / \mathrm{v})$ chloroform (100\% death) were equivalent to values obtained after prolonged exposure to heat. Light microscopy was carried out using a Zeiss Axioimager Z1 Microscope (Carl Zeiss AG, Germany) at the Integrated Microscopy Facility, The Biotron, Western University.

\section{Gas Chromatography - Mass Spectrometry and Metabolomic Analysis}

Algae were grown in three biological replicates at $4^{\circ} \mathrm{C}, 10^{\circ} \mathrm{C}$ and $15^{\circ} \mathrm{C}$ and sampled at a steady-state temperature or after $6 \mathrm{~h}$ exposure to $24^{\circ} \mathrm{C}$. Cells were harvested by centrifugation $(6,000 \mathrm{~g}, 5 \mathrm{~min})$, washed once with fresh medium, flash frozen in liquid $\mathrm{N}_{2}$ and stored at $-80^{\circ} \mathrm{C}$. Metabolite extractions, chromatography and quality processing were done at the West Coast Metabolomics Center (UC Davis, CA, USA), following a previously established protocol optimized for retention and separation of primary metabolite classes (amino acids, carbohydrates, sugar acids, sterols, aromatics, nucleosides, amines and miscellaneous compounds (Fiehn et al. 2008). Mass spectra were processed using BinBase, and analysed as described in (Fiehn, Wohlgemuth \& Scholz 2005). Metabolites were identified based on their mass spectral characteristics and GC retention times by comparison with compounds in a plant and algae reference library (West Coast Metabolomics Center). Peak heights for the quantification ion at the specific retention index corresponding to each metabolite were normalized by the sum of peak heights in the sample. Normalized data were processed by cube root transformation followed by range scaling. All statistical analyses were performed by the Metaboanalyst 4.0 software suite (Chong et al.2018) and included principal component analysis (PCA), analysis of variance (ANOVA), heatmap and clustering analysis using Ward's linkage for clustering and Pearson's correlation as a measure of dissimilarity.

\section{RNA Sequencing and Transcriptomic Analysis}

Nucleic acids were isolated from frozen cell pellets using a modified CTAB protocol (Possmayer et al. 2011). RNA concentration was determined using a Nanodrop2000 (Thermo-Fisher Scientific) and integrity was assessed with a 2100 Bioanalyzer (Agilent Technologies, USA). RNA library preparation and sequencing were performed by Genome Quebec (Montreal, QC, Canada). Libraries were generated from $250 \mathrm{ng}$ of total RNA. Poly-A mRNA was isolated with the NEBNext Poly(A) mRNA Magnetic Isolation kit (NEB, USA). Reverse transcription was performed with the NEBNext RNA First Strand Synthesis kit (NEB), and second strand synthesis with the NEBNext Ultra Directional RNA Second Strand Synthesis kit (NEB). Libraries were prepared using the NEBNext Ultra II Library Prep Kit for Illumina (NEB) and were sequenced with 100 base paired-end reads on an Illumina HiSeq4000 platform (Illumina, San Diego, USA). 
For gene expression analysis, the RNA-Seq reads were mapped to the UWO241 assembled genome (Zhang et al. 2021a) (Accession number GCA_016618255.1) using HISAT2 (Kim, Langmead \& Salzberg 2015) and counted against the predicted gene models using HTSeq-count v0.11.3 (Anders, Pyl \& Huber 2015). Stringtie v2.1.5 was used to generate expression estimates from the SAM/BAM files created by HISAT2 (Pertea, Kim, Pertea, Leek \& Salzberg 2016). Samtools v1.11 was used to read and write Illumina RNA-Seq alignments in the SAM and BAM files. The total number of aligned reads were normalized by gene length and sequencing depth and expressed as Fragments Per Kilobase of transcript per Million mapped reads (FPKM) as a measure of the expression level for each gene. Differentially expressed genes (DEGs) were determined by Ballgown v2.22.0 (Perteaet al. 2016) and edgeR v2.22.0 (Robinson, McCarthy \& Smyth 2010). Genes were sorted according to their $\log 2$ (read counts)-transformed values. The Generally Applicable Gene-set Enrichment (GAGE v2.40.1) package in R (Luo, Friedman, Shedden, Hankenson \& Woolf 2009) was used to perform pathway analysis based on genes that were assigned Chlamydomonas Entrez IDs. The parameter "same.dir" in GAGE was set in True and significantly regulated pathways were defined as those enriched sets of genes with a p-value $<0.05$. To generate the heatmap expression profiles of HSPs, hierarchical clustering using the Euclidean distance method was performed within each subfamily using the ComplexHeatmap R package. Venn diagrams were constructed using an online tool (http://bioinformatics.psb.ugent.be/webtools/Venn/).

\section{Identification of HSP genes in green algal genomes}

The UWO241 genome (Zhang et al. 2021a) was screened for the presence of HSP genes using C. reinhardtii HSP protein sequences (Phytozome v12.1) and conserved domains typical for HSPs from the Pfam database (Mistry et al. 2021) as queries. Putative HSP genes in UWO241 were identified through a tBLASTn search (e-value $<\mathrm{e}^{-10}$, bit-score $>100$ ). The results were manually inspected for redundant sequences and to ensure correct gene structure annotation. The presence of conserved HSP domains was confirmed using Pfam and NCBI Conserved Domain Database (Luet al. 2020). The gene names are based on the closest C. reinhardtii homologs and multiple homologous sequences were numbered in order of discovery (e.g., HSP70A-1). Only genes supported by transcriptomic data are reported. The genomes of other green algae were obtained from GenBank (Chlamydomonas. sp. ICE-L (Zhang et al. 2020); Chlamydomonas eustigma (Hirooka et al.2017); Gonium pectorale (Hanschen et al. 2016); Chlorella sorokiniana (Arriola et al. 2018)) or Phytozome V12.0 (Dunaliella salina (Polle et al. 2017); Volvox carteri (Prochnik et al. 2010); Coccomyxa subellipsoidea(Blanc et al. 2012)) and similarly screened. Only full-length genes were used in downstream analyses. Multiple sequence alignments were performed using ClustalW (Sievers et al. 2011) implemented through Geneious Prime (Biomatters Ltd, Auckland, New Zealand). Cladograms and phylogenetic trees were inferred based on protein alignments using FastTree v.2.1 with the Neighbor-Joining method and the Jukes-Cantor genetics distance model (Price, Dehal \& Arkin 2010), and annotated in iTOL v6 (https://itol.embl.de/). The bootstrap values for each branch reflect the percentage on 1,000 replicate trees. Subcellular localization was predicted by four independent software: TargetP2.0 (Armenteros et al. 2019), Predotar (Small, Peeters, Legeai \& Lurin 2004), WoLF PSORT (Horton et al. 2007) and LOCALIZER (Sperschneider et al. 2017).

\section{SDS-PAGE and Immunoblotting}

Algal cells were harvested by centrifugation $(5,000 \mathrm{~g}, 5 \mathrm{~min})$, resuspended in in $0.1 \mathrm{M} \mathrm{Na}_{2} \mathrm{CO}_{3}$ containing 0.1 $\mathrm{M}$ DTT, and frozen at $-20^{\circ} \mathrm{C}$ for $1 \mathrm{hr}$. Protein samples were solubilized with $5 \%(\mathrm{w} / \mathrm{v})$ SDS and $30 \%(\mathrm{w} / \mathrm{v}$ ) sucrose, and heated to $85^{\circ} \mathrm{C}$ for $5 \mathrm{~min}$. The protein content was quantified using a protein quantification kit (Pierce BCA Protein Assay Kit, ThermoFisher Scientific) and loaded on equal protein basis. Electrophoresis and protein transfer was performed as described before (Szyszka-Mroz, Pittock, Ivanov, Lajoie \& Hüner 2015). Membranes were probed with primary antibodies raised against $C$. reinhardtii and specific for HSP70A (1:3,000), HSP70B (1:10,000) (Agrisera, Vännäs, Sweden); CPN60A (1:5,000), HSP90A (1:1,500), HSP90C $(1: 5,000)$ (a kind gift from M. Schroda), predicted to bind specifically to their closest homologs in UWO241. HRP-conjugated secondary antibody was used (1:10,000; Sigma-Aldrich), and antibody-protein complexes were visualized using enhanced chemiluminescence detection reagents (GE Healthcare). Protein amounts were quantified by densitometry using ImageJ (National Institutes of Health, Bethesda, MA, USA).

\section{Accession numbers}


Sequence data can be found in GenBank/EMBL and Phytozome v12.1 under accession numbers listed in Supplemental Table S1. Original RNA-Seq data from this article are deposited at the NCBI database (BioProject: PRJNA701568; BioSample: SAMN17886321-38).

\section{RESULTS}

\section{The growth and metabolic make-up of UWO241 and C. reinhardtii at low temperature}

In its native environment, UWO241 is exposed to year-round low temperatures $\left(4^{\circ} \mathrm{C}-6^{\circ} \mathrm{C}\right)$. A culturing temperature of $4^{\circ} \mathrm{C}$ supported a robust growth $\left(\sim 0.22\right.$ day $\left.^{-1}\right)$, but maximal growth rates were achieved at $10^{\circ}-15^{\circ} \mathrm{C}\left(0.25-0.30\right.$ day $\left.^{-1}\right)$. As an obligate psychrophile, UWO241 did not grow at $20^{\circ} \mathrm{C}$ (Figure 1a). In accordance with previous reports (Schrodaet al. 2015), C. reinhardtii exhibited maximal growth rates at $20^{\circ} \mathrm{C}-28^{\circ} \mathrm{C}\left({ }^{\sim} 0.6\right.$ day $\left.^{-1}\right)$, lower rates at temperatures both higher and lower than this range (Figure $\left.1 \mathrm{~b}\right)$ and was unable to grow $<10^{\circ} \mathrm{C}$. C. reinhardtii cultures were able to grow at $10^{\circ}$ and $15^{\circ} \mathrm{C}$, albeit at a decreased rate $\left(0.25-0.32\right.$ day $\left.^{-1}\right)$ compared to growth at $28^{\circ} \mathrm{C}$ (Figure $\left.1 \mathrm{~b}\right)$, but notably the rates were similar to those of UWO241 between $10^{\circ}-15^{\circ} \mathrm{C}$ (Figure 1a).

Untargeted analysis of the primary metabolome of both species acclimated to different temperatures $\left(4^{\circ} \mathrm{C}\right.$, $10^{\circ} \mathrm{C}, 15^{\circ} \mathrm{C}-\mathrm{UWO} 241 ; 10^{\circ} \mathrm{C}, 15^{\circ} \mathrm{C}, 28^{\circ} \mathrm{C}-$ C. reinhardtii) detected 771 unique metabolites, 163 of which were positively identified based on their mass spectra and retention times (Kind et al. 2009). PCA analysis revealed that the metabolic status of $C$. reinhardtiiwas dependent on the culturing temperature and differed between both components. This contrasted with UWO241 where temperature had minimal effects on the overall metabolic status, and we observed only nominal separation between the cultures grown at different temperatures (Figure 2). Differentially accumulated metabolites (DAMs) were defined as those exhibiting a 2fold change (FC) in accumulation between treatments $(\mathrm{p}<0.01$, ANOVA, Tukey's post-hoc). The metabolome of $C$. reinhardtii responded strongly to growth temperature with $273(35 \%)$ DAMs at $10^{\circ} \mathrm{C}$ compared to the optimal temperature of $28^{\circ} \mathrm{C}$. This response was temperature dependent, with cultures at $15^{\circ} \mathrm{C}$ exhibiting a similar metabolite profile but with a decreased magnitude of the response (72 DAMs, 9\%) (Figure 3a). The metabolic profile of UWO241 was similar regardless of the culturing temperature. Cultures at $10^{\circ} \mathrm{C}$ and $15^{\circ} \mathrm{C}$ had only $78(10 \%)$ and $48(6 \%)$ DAMs when compared to $4^{\circ} \mathrm{C}$ (Figure 3a). These findings indicate that the mesophile grown at low temperatures adjusts its metabolome as an acclimation to cold, while the primary metabolome of the psychrophile is less affected by culturing temperature.

Next, we analyzed the 163 primary metabolites with positively identified chemical signatures by comparing all samples to the metabolome of C. reinhardtii grown at $28^{\circ} \mathrm{C}$ (Figure 3b; Supplemental Dataset S1). We present the 20 metabolites that have the largest differences in abundance between the treatments (Table 1). Carbohydrates and glycerol are well-known cryoprotectants in cold-adapted plants and algae (Roser, Melick, Ling \& Seppelt 1992; Tulha, Lima, Lucas \& Ferreira 2010; Leya 2013; Su et al. 2016). We observed high accumulation of several carbohydrates (trehalose, maltose, and fructose) and glycerol metabolism intermediates in C. reinhardtii grown at $10^{\circ} \mathrm{C}$. UWO241 accumulated these compounds constitutively, regardless of culturing temperature (Figure 3b; Supplemental Dataset S1). Carboxylic acids and TCA cycle intermediate accumulation showed a strong dependence on growth temperature and was increased at the lowest temperature for both algae. Notably, $\alpha$-ketoglutarate $(\alpha-K G)$, 3-phosphoglycerate (3-PGA), and phosphoenolpyruvate (PEP) showed the highest increases in abundance in UWO241 grown at $4^{\circ} \mathrm{C}$ (FC 48.1, 39.8, and 18.0 respectively). Lactic acid is the exception: its abundance is significantly increased in the mesophile $\left(\mathrm{FC} 70.2\right.$ at $\left.10^{\circ} \mathrm{C}\right)$ but decreased in the psychrophile $\left(\mathrm{FC} 6.7\right.$ at $\left.4^{\circ} \mathrm{C}\right)$. We also detected high accumulation of dehydroascorbic acid in both C. reinhardtii at $10^{\circ} \mathrm{C}$ (FC 19.7) and UWO241 at all temperatures (FC 12.4-22.5) (Table 1). Threonic acid, a product of ascorbate catabolism (Debolt, Melino \& Ford 2007), showed a similar pattern, suggesting an important role for the ascorbate pathway during low temperature growth.

We observed species-specific differences in the primary metabolomes. Glucose, which has known roles in osmotolerance and cold stress (Demmig-Adams, Garab, Adams III, \& Govindjee 2014; Taïbi et al.2018), was present at lower levels in UWO241 compared to C. reinhardtii, regardless of the temperature (FC 24-81). Sugar alcohols are important molecules in cold-stress tolerance in plants and algae (Roser et al. 1992; 
Leya 2013); their accumulation was increased in C. reinhardtii but not in UWO241 (Figure 3b), although both species showed a significant decrease in several sugar alcohols (mannitol and galactinol; Table 1) at low temperatures. Amino acid metabolism was significantly affected by low temperature in C. reinhardtii and nearly all detected amino acids increased in abundance. Again, we did not observe this in UWO241, and amino acid abundance was largely unchanged or decreased (Figure 3b; Table 1; Supplemental Dataset $\mathrm{S} 1)$. An exception is the non-proteinogenic amino acid ornithine, which accumulated at low temperatures in both species. In $C$. reinhardti i, this accumulation was temperature dependent (higher at $10^{\circ} \mathrm{C}$ than at $28^{\circ} \mathrm{C}, \mathrm{FC} 9.7$ ), whereas in UWO241 it is constitutively high at all temperatures (FC $33.5-34.7$; Table 1). $\mathrm{N}$-containing compounds, including those involved in purine and pyrimidine metabolism, exhibited colddependent accumulation in C. reinhardtii ; however, we observed the opposite trend in UWO241 where $\mathrm{N}$-compounds accumulated at higher levels at $15^{\circ} \mathrm{C}$ when compared to $4{ }^{\circ} \mathrm{C}$ (thymidine, Figure $3 \mathrm{~b}$, Table 1; Supplementary Dataset S1). Altogether, we suggest that these data reflect a metabolic switch in the primary metabolism of UWO241 due to life in a perennially cold environment. UWO241 appears to retain an active energy metabolism at low temperatures, which fuels the constitutive accumulation of stress-related compounds across a range of growth temperatures.

\section{Highest growth rates do not correlate with resistance to heat stress in UWO241.}

To test whether growth temperature affects heat stress sensitivity, UWO241 and C. reinhardtii were exposed to non-permissive temperatures $\left(24^{\circ} \mathrm{C}\right.$ and $42^{\circ} \mathrm{C}$, respectively). To ensure sufficient but non-lethal stress, we based these treatments on previous heat stress studies in UWO241 (Possmayer et al. 2011) and C. reinhardtii (Hemme et al. 2014; Légeret et al. 2016), which showed that the response of $C$. reinhardtii to $42^{\circ} \mathrm{C}$ was broadly comparable to the that of UWO241 to $24^{\circ} \mathrm{C}$. To quantify the effects of heat stress, we measured cell death using Evans Blue dye that accumulates in cells with damaged membranes (Supplemental Figure S1). UWO241 cultured at $10^{\circ} \mathrm{C}$ and $15^{\circ} \mathrm{C}$ (temperatures that lead to the fastest growth), completely lost viability after $72 \mathrm{~h}$ exposure. In contrast, UWO241 cultures grown at $4^{\circ} \mathrm{C}$ (with slower growth), were more resistant to $24^{\circ} \mathrm{C}$ exposure and suffered only $57 \%$ cell death at $72 \mathrm{~h}$ (Figure $4 \mathrm{a}$ ). Cell structures and chlorophyll were detected under the light microscope only in the $4^{\circ} \mathrm{C}$-grown UWO241 after $72 \mathrm{~h}$ exposure to $24^{\circ} \mathrm{C}$, but not in the $10^{\circ} \mathrm{C}$ and $15^{\circ} \mathrm{C}$ ones (Figure 4c). C. reinhardtii was most resistant to $42^{\circ} \mathrm{C}$ when initially grown at of $28^{\circ} \mathrm{C}$ with fastest growth rates, showing $30 \%$ cell death at $48 \mathrm{~h}$. Cultures acclimated to lower $\left(10^{\circ} \mathrm{C}\right)$ and higher $\left(37^{\circ} \mathrm{C}\right)$ temperature were more sensitive to heat exposure and rapidly lost viability $(70 \%$ and $90 \%$, respectively) by $48 \mathrm{~h}$. All cultures appeared to be completely dead after $72 \mathrm{~h}$ exposure (Figure $4 \mathrm{~b}$ ). Similar patterns of chlorophyll loss (Supplementary Figure S2) and cell structure were confirmed by light microscopy (Supplemental Figure S3).

\section{Heat shock induced global metabolomic and transcriptomic changes in UWO241.}

Next, we examined global metabolomic heat-induced changes in UWO241 cultures grown at $4^{\circ} \mathrm{C}, 10^{\circ} \mathrm{C}$ and $15^{\circ} \mathrm{C}$ and subsequently exposed to heat stress at $24^{\circ} \mathrm{C}$ for 6 hours. PCA analysis of all 771 detected metabolites demonstrated a separation along both principal components between the metabolome of the UWO241 cultures grown at $4^{\circ} \mathrm{C}$ and the metabolome of the same cultures exposed to $24^{\circ} \mathrm{C}$ (Figure 5). We also observed a separation between the metabolomes of UWO241 grown at $10^{\circ} \mathrm{C}$ and those exposed to heat, albeit only along PC2. There was minimal separation along either component between the cultures acclimated to $15^{\circ} \mathrm{C}$ before the $6 \mathrm{~h}$ heat stress (Figure 5). HCA (Figure 6a) revealed the strongest response when cultures grown at $4^{\circ} \mathrm{C}$ were exposed to $24^{\circ} \mathrm{C}$ for $6 \mathrm{hrs}(222 \mathrm{DAMs}, 29 \%)$. This heat stress response was attenuated in cultures acclimated to $10^{\circ} \mathrm{C}$, and even more so in the cultures acclimated to $15^{\circ} \mathrm{C}$, with $71(9 \%)$ and $26(3 \%)$ DAMs after heat exposure, respectively.

Next, we compared the accumulation of all 163 positively identified metabolites (Figure 6b, Supplemental Dataset S2) and report the 20 metabolites that showed the largest abundance difference between steady-state and heat stress (Table 2). Most major metabolite classes, including carbohydrates, sugar alcohols, amino acids, lipids, and antioxidants, increased in abundance in the cultures grown at $4^{\circ} \mathrm{C}$ and exposed to $24^{\circ} \mathrm{C}$, except for carboxylic acids and sugar phosphates which increased significantly in the $10^{\circ} \mathrm{C}$ cultures (but not in those grown at $15^{\circ} \mathrm{C}$ ). These metabolites are already present in high amounts in UWO241 acclimated to 
$4^{\circ} \mathrm{C}$ (Figure 3b). Ergosterol (FC 439.1) and $\alpha$-tocopherol (FC 308.1) increased at very high amounts in all cultures exposed to heat, regardless of the initial conditions (Table 2). These increases follow a temperature dependent pattern, with the highest $\mathrm{FC}$ seen in the cultures acclimated to $4^{\circ} \mathrm{C}$ prior to heat shock.

Using the same experimental design we examined transcriptomic responses with RNA-Seq analysis based on the 16,325 gene models in the functionally annotated UWO241 genome (Zhang et al. 2021a). Differentially expressed genes (DEGs) were defined as those having an absolute FC $>4$ and a p-value $<0.05$. Similar to the metabolomic analyses (Figure 2; Figure 3), we found that steady-state culturing temperature had only a very minor effect on the overall transcriptome status in UWO241, with $<3 \%$ of the total number of genes encoded in the UWO241 genome being identified as DEGs in the $10^{\circ} \mathrm{C}$ and $15^{\circ} \mathrm{C}$-grown cultures, when compared to those at $4^{\circ} \mathrm{C}$ (Figure 7a, 7b; Supplementary Dataset S3). Exposure to $24^{\circ} \mathrm{C}$ induced a significant heat-induced response at the level of the transcriptome. The cultures acclimated to $10^{\circ} \mathrm{C}$ exhibited the strongest response with 1909 DEGs (11.7\%; 939 up- and 970 down-regulated), followed by the cultures grown at $4^{\circ} \mathrm{C}$ with 1610 DEGs $\left(9.8 \% ; 826\right.$ up- and 784 down-regulated). The cultures grown at $15^{\circ} \mathrm{C}$ were the least responsive to heat stress with 837 DEGs (5.1\%; 456 up- and 381 down-regulated) (Figure 7c, 7d; Supplementary Dataset S4). Regardless of the initial culturing temperature, pathways enriched for up-regulated DEGs included those in protein processing and endocytosis (Table 3; Supplementary Dataset S5). Pathways involved in energy metabolism, nucleic acid metabolism, amino acid metabolism, ribosome biogenesis, fatty acid biogenesis and cofactor synthesis were enriched in down-regulated DEGs (Table 3; Supplementary Dataset S5).

\section{HSP gene family and expression profiling in UWO241 under heat stress}

HSPs are highly conserved among evolutionary distant species and are often used as molecular heat-stress markers. We identified a total of 55 full-length, transcript-supported HSP genes in the UWO241 genome (Table 4, Supplementary Dataset S6). This number was quite large compared to that reported for the C. reinhardtii genome (41 full-length HSP genes) (Schroda \& Vallon 2009) (Table 4). This expansion in the HSP gene family could be related to the extremophilic lifestyle of UWO241 or simply due to the more distant evolutionary relationship between UWO241 and C. reinhardtii (Possmayer et al. 2016). To distinguish between these possibilities, we screened the genomes of other green algae with publicly available draft nuclear genome sequences. We detected the highest number of HSP genes in the two psychrophiles: UWO241 (55) and ICE-L (51). The subfamilies containing HSP100s, HSP60s and small HSPs were significantly expanded in both species (Table 4; Supplementary Dataset S6); however, UWO241 had more HSP70 genes and ICE-L had more HSP90 genes.

Previous work identified widespread duplication events in the UWO241 genome, including hundreds of highly similar full-length duplicate genes (HSDs; [?]90\% pairwise identity) (Zhang et al. 2021a; Zhang, Hu \& Smith 2021b). Indeed, our analysis revealed that certain C. reinhardtii HSP genes had multiple homologs in the UWO241 genome (ClpB3, HSP70A, HSP70D, HSP70G, CPN60A, HSP22A). Not all of these qualify as duplicates according to the strict cut-off used by Zhanget al . (2021), but nevertheless they share a high \% identity at the amino acid level (55-94\%) and contain highly conserved domains important for HSP function (Supplementary Dataset S6; Supplementary Figure S4). The HSP70 gene subfamily was the most expanded one in UWO241, primarily due to a total of 6 cytosolic HSP70A isoforms. The other psychrophilic alga ICE-L encoded 3 cytosolic HSP70A genes, while the genomes of the other explored species encoded for only one or two cytosolic HSP70A genes (Supplementary Figure S5).

To examine whether HSP gene expression is affected by temperature in UWO241, all full-length HSP genes were profiled using the RNA-Seq dataset described above. HSPs are induced by cold stress in C. reinhardtii (Maikova et al, 2016) and we asked whether the steady-state culturing temperature (4degC, 10degC, 15degC) affects HSP expression in UWO241. Most HSP genes were not significantly regulated in the cultures grown at different steady-state temperatures, except for ClpB1, HSP70B-2 and all HSP22A homologs that were either down-regulated or below the detection threshold in the 10degC cultures compared to those at 4degC (Figure 8). This suggests that steady-state temperature has only a minor effect on HSP regulation in UWO241. Some HSPs had high expression under steady-state conditions, in this case defined as FPKM $>100$ (Supplementary Dataset S3). These include all members of the HSP90 and CPN60 families, one HSP100 gene (ClpB3-4) 
and some (but not all) members of the HSP70 family (HSP70A-1 and -2, HSP70B-1, HSP70C, HSP70E and BIP1).

Exposure to heat stress for 6 hours induced the expression of some, but not all, HSP genes. (Figure 8, Supplementary Table 5). Most highly expressed transcripts at steady-state conditions were not upregulated under heat stress, apart from HSP90A, which was up-regulated. The genes with largest expression differences between steady-state and heat stress were the HSP22A homologs (HSP22A-2, -3, -6 to -9; FC[?]7-32,000), followed by several HSP70 (HSP70A-3 to A-5, HSP70B-2) and ClpB (ClpB3-1, ClpB1) homologs (Figure 8; Supplementary Dataset S6). These data imply that some HSPs may have homeostatic roles and are constitutively expressed at high levels under steady-state conditions while others may play stress-related roles.

\section{HSP protein accumulation in UWO241 and C. reinhardtii}

Next, we investigated whether HSP expression trends are mirrored at the protein level using antibodies for several major HSPs in UWO241 and C. reinhardtii. In the first set of experiments, we cultured both species at a range of temperatures, including the highest temperature that can support growth (4-17degC for UWO241; 22-37degC for C. reinhardtii ). The cytosolic HSP70A, HSP90A, and the chloroplast CPN60A exhibited higher protein levels in UWO241 when compared to C. reinhardtii at most culturing temperatures (Figure 9). HSP70B accumulated at comparable levels in both species, especially at higher growth temperatures, while HSP90C was lower in UWO241 in comparison to C. reinhardtii (Figure 9, Supplementary Figure S6). The steady-state culturing temperature had only a minor effect on HSP accumulation, with four of the tested HSPs (CPN60A, HSP70A, HSP90A, HSP90C) accumulating at slightly higher levels at 4degC when compared to higher growth temperatures in UWO241 (Figure 9, Supplementary Figure S6). To test whether the high accumulation of HSPs is due to growth at low temperatures regardless of the species, we also cultured C. reinhardtii at $15 \mathrm{degC}$ and $10 \mathrm{degC}$. We compared low temperature HSP accumulation to that at optimal growth conditions (28degC) and to cultures exposed to heat shock (42degC) for 6 hours. Algal cultures that were acclimated to $10 \mathrm{degC}$ and $15 \operatorname{deg} \mathrm{C}$ accumulated HSPs at much higher levels than those acclimated to $28 \mathrm{degC}$ and at comparable levels to those exposed to heat shock at $42 \mathrm{degC}$ (Figure 10). These data suggest that accumulation of high HSP levels could be an adaptive strategy for low temperature growth in green algae.

HSP gene expression and protein accumulation is strongly induced by heat stress in C. reinhardtii (Muhlhaus et al. 2011; Schmollinger et al. 2013). To test whether the same is true for an obligate psychrophile, we exposed UWO241 cultures grown at $4 \mathrm{degC}, 10 \mathrm{degC}$ and $15 \mathrm{degC}$ to heat stress $(24 \mathrm{deg} \mathrm{C})$ for 6 hours. We applied an equivalent treatment to $C$. reinhardtii grown at low (10degC), optimal (28degC) and high (37degC) temperature by exposing the cultures to heat shock (42degC) for 6 hours. Most C. reinhardtii HSPs increased in abundance during heat shock, including the HSF1 transcription factor, regardless of the initial culturing temperature (Figure 11). HSP accumulation was induced even in cultures acclimated to $10 \mathrm{degC}$, which accumulated high HSP amounts prior to the heat shock (Figure 6b, Figure 7). In contrast, heat shock had only a very minor effect on HSP accumulation in UWO241, and HSP accumulation did not significantly increase with heat stress, regardless of the initial culturing temperature (Figure 7b, 7d). We could not detect HSF1 in UWO241, either due to low antibody specificity or very low protein levels. Thus, HSP accumulation is significantly induced by heat stress in the mesophile but not appreciably in the psychrophile.

\section{DISCUSSION}

\section{Metabolic signatures of adaptation to permanently low temperatures}

Algae exhibit the fastest growth rates under optimal conditions, whereas stress can threaten their cellular homeostasis and lead to decreased growth rates and reduced fitness (Borowitzka 2018). The Antarctic alga, UWO241, experiences low but very stable temperatures of 4-6degC year-round, but we found that its growth rate is fastest at $10 \mathrm{deg} \mathrm{C}$ and $15 \mathrm{deg} \mathrm{C}$ (Figure 1). This indicates that the biochemical and metabolic processes operating in UWO241 are better adjusted to higher temperatures than what it experiences in 
nature (4degC). Nevertheless, we showed that UWO241 is, indeed, adapted for life at 4degC, which is reflected in the fact that light- and $\mathrm{CO}_{2}$-saturated rate of $\mathrm{O}_{2}$ evolution for $\mathrm{UWO} 241$ at this temperature are comparable to the photosynthetic rate of C. reinhardtii grown at 28degC (Pocock, Vetterli \& Falk 2011). The primary metabolome of 4degC-grown UWO241 did not differ significantly from that of cultures at their optimal growth temperatures of $10 \mathrm{degC}$ to $15 \mathrm{deg}$. In contrast, C. reinhardtii showed a strong temperature dependent response at the level of the primary metabolome (Figure 2, Figure 3a). The 10degC-grown $C$. reinhardtii cultures accumulated increased levels of cryoprotectants and membrane stabilizers than cultures grown at their optimal temperature (28degC), a common response in photosynthetic organisms during cold stress (Wanner \& Junttila 1999; Gray \& Heath 2005; Kaplanet al. 2007; Guy, Kaplan, Kopka, Selbig \& Hincha 2007; Janska, Maršík, Zelenková \& Ovesná 2010; Fürtauer, Weiszmann, Weckwerth \& Nägele 2019). We interpret this as evidence that the psychrophile UWO241 does not exhibit typical cold stress responses when cultured at $4^{\circ} \mathrm{C}$, despite its slow growth rates.

Our data reveal a steady-state re-routing of primary metabolism in UWO241 when compared to the mesophilic model C. reinhardtii. We detected the constitutive accumulation of several metabolites with known stress functions in UWO241, regardless of the growth temperature, while the same metabolites only accumulated at high levels in $10^{\circ} \mathrm{C}$-grown C. reinhardtii . First, soluble sugars have known cryoprotectant roles in cold-adapted plants and algae (Tulha et al. 2010; Leya 2013; Su et al. 2016). Most detected soluble sugars (trehalose, sucrose, ribose, maltose, fructose) accumulated at high levels in all UWO241 cultures but only in $10^{\circ} \mathrm{C}$-grown C. reinhardtii (Table 1; Supplemental Dataset S1). This suggests that the psychrophile has a re-wired central carbon metabolism and accumulates high amounts of carbohydrates at the expense of other photosynthetic intermediates, consistent with previous studies (Cook et al. 2019; Kalraet al. 2020).

Second, we observed similar patterns with ascorbic acid (AsA) and its oxidized form dehydroascorbic acid (DHA) (Table 1; Supplemental Dataset S1). The ascorbate-glutathione (AsA-GSH) cycle is a fundamental metabolic pathway involved in maintenance of cellular redox homeostasis during cold stress in many photosynthetic species (Dreyer \& Dietz 2018; Hasanuzzaman et al. 2019). Thus, UWO241 and other organisms that live in perpetually cold environments may need a robust and constitutively active antioxidant system to cope with high ROS levels. Third, the non-proteinogenic amino acid ornithine also accumulated at high levels in UWO241 at all growth temperatures, but only at $10^{\circ} \mathrm{C}$ in C. reinhardtii (Table 1). Ornithine plays a pivotal role in polyamine, arginine and proline biosynthesis, and its accumulation has been linked to increased stress tolerance in plants (Kalamaki et al. 2009a; Kalamaki, Merkouropoulos \& Kanellis 2009b; Ghahremaniet al. 2014). We also detected the increased amount of the polyamine putrescine in UWO241 compared to C. reinhardtii (and no increases in arginine or proline, Supplemental Dataset S1). High ornithine and polyamine levels may play a role in DNA and RNA protection and stabilization, protein synthesis, and cell cycle progression at low temperatures (Gill \& Tuteja 2010; Minocha, Majumdar \& Minocha 2014; Chen, Shao, Yin, Younis \& Zheng 2019). Taken together, we suggest that in UWO241 the accumulation of stress-related compounds, such as soluble sugars, antioxidants and polyamines, represents a mechanism to ensure efficient metabolism, redox homeostasis and cell division at low temperatures. Unlike C. reinhardtii, where accumulation of stress-metabolites is induced by cold, in UWO241 these protective compounds constitutively accumulate across a range of permissive growth temperatures.

\section{Can Antarctic algae mount a functional heat shock response?}

A defining characteristic of psychrophiles is their inability to grow at moderate temperatures (Cvetkovska et al. 2017), but the underlying reasons for this sensitivity are unknown. In this work we showed that despite living in a permanently cold environment, UWO241 can mount HSR at the level of the primary metabolome and transcriptome. We also showed, however, that the response to heat stress in UWO241 is dependent on the initial culturing temperature. UWO241 grown at $4^{\circ} \mathrm{C}$ and then exposed to $24^{\circ} \mathrm{C}$ resulted in the slowest cell death kinetics (Figure 4a, 4c) and a strong response at the level of its primary metabolome (Figure 6) and transcriptome (Figure 7c, $7 \mathrm{~d}$ ). UWO241 cultures grown at $10^{\circ} \mathrm{C}$ exhibit a strong response when exposed to heat for 6 hours but only at the level of the transcriptome (Figure 6, Figure 7). A response at the level of the metabolome is largely absent, except for increased accumulation of carboxylic acids and sugar phosphates 
(Figure 6b). Cultures initially grown at $15^{\circ} \mathrm{C}$ exhibited an attenuated response at both the metabolome (Figure 6) and the transcriptome (Figure $7 \mathrm{c}, 7 \mathrm{~d}$ ). Both $10^{\circ} \mathrm{C}$-grown and $15^{\circ} \mathrm{C}$-grown UWO241 cultures were less resistant to $24^{\circ} \mathrm{C}$ exposure and had faster cell death kinetics (Figure 4a, 4c). This study demonstrates that UWO241 cultured at a temperature closest to its natural environment $\left(4^{\circ} \mathrm{C}\right)$ has the highest capacity to respond to heat stress, despite slow growth rates.

The stress metabolism in UWO241 appeared to be routed towards the accumulation of soluble sugars, antioxidants and cryoprotectants (Figure 6b). Many of these compounds are metabolic markers for cold stress in mesophiles and are already present in high amounts in non-stressed UWO241 cells (Figure 3b). The metabolites ergosterol and $\alpha$-tocopherol showed the most dramatic increases in accumulation between steady-state and heat-stressed cultures, with the largest increases seen in the cultures initially grown at $4^{\circ} \mathrm{C}$ (Table 2, Supplemental Table S2). The tocopherol antioxidant system has been studied during high light stress (Trebst, Depka \& Holländer-Czytko 2002; Sirikhachornkit, Shin, Baroli \& Niyogi 2009; Nowicka \& Kruk 2012; Szarka, Tomasskovics \& Bánhegyi 2012), and to the best of our knowledge this is the first report of its involvement in heat stress in green algae. In yeast, increased ergosterol content and re-modelling of the lipid composition of cellular membranes to has been shown to counteract the deleterious effects of several stressors, including heat (Swan \& Watson 1998; Vanegas, Contreras, Faller \& Longo 2012; Caspeta et al. 2014; Godinhoet al. 2018); however a detailed lipidomic analysis is required to test whether a similar process is operational in UWO241.

In accordance with the metabolome data, a steady-state culturing temperature appeared to have only a minor effect on the UWO241 transcriptomic make-up (Figure 7a, 7b), but heat stress induced a stronger response (Figure 7b, 7c). In UWO241, up to $11.7 \%$ of all nuclear-encoded genes were differentially regulated by heat stress $\left(10^{\circ} \mathrm{C}\right.$-grown cultures, Figure $\left.4 \mathrm{a}, 4 \mathrm{~b}\right)$. Broadly speaking, this response seems to be of a lesser intensity as compared to that of C. reinhardtii when exposed to $25 \mathrm{~min}$ of heat stress $\left(25^{\circ} \mathrm{C} 42^{\circ} \mathrm{C}\right)$, which results in approximately 19\% DEGs (Légeret et al. 2016). When the green algal halophile Dunaliella bardawil was exposed to heat stress $\left(25^{\circ} \mathrm{C} 42^{\circ} \mathrm{C}\right)$ for 2 hours, it exhibited a similar transcriptomic response as we observed for UWO241 with $12 \%$ of all transcripts identified as DEGs (Liang, Jiang, Wang \& Zhu 2020). Direct comparisons between studies involving different species, culturing conditions, and time points are difficult; however, we observed that in UWO241 (Table 3), C. reinhardtii (Légeret et al. 2016) and D. bardawil (Liang et al. 2020), the few pathways enriched in up-regulated genes are those involved in protein processing, which include HSPs. This suggests a conserved role for protein processing pathways between UWO241 and related mesophilic algae during HSR.

\section{High accumulation of HSPs in UWO241 could have adaptive roles at low temperature.}

HSPs are one of the first hallmarks of the HSR and key component of protein synthesis, folding, and the prevention of protein aggregates during heat stress (Schroda et al. 2015). Screening of the UWO241 genome revealed more putative HSP genes than any other green alga examined to date (Table 4, Supplementary Figure S4). This expansion is mostly driven by multiple copies of a few genes, including six (6) ClpB3 and HSP70A genes, three (3) CPN60A genes and no less than ten (10) HSP22A genes homologous to those in $C$. reinhardtii . The genome of psychrophilic Antarctic sea-ice green alga ICE-L also encodes for a significantly more HSP genes as compared to non-psychrophilic species (Table 4). UWO241 belongs to the Moewusinia clade of the order Chlamydomonadales (Possmayer et al. 2016), while ICE-L is a member of the closely affiliated Monadinia clade (Zhang et al.2020). This suggests that an expanded HSP gene family may be a consequence of life in the permanent cold, and not a feature common to a particular algal clade.

Sequencing of the UWO241 genome revealed an unusually large (212 Mb) nuclear genome with hundreds of highly similar duplicate (HSD) genes from diverse cellular pathways (particularly in protein translation, DNA packaging and photosynthesis), more than any other algal species with a sequenced genome (Zhang et al, 2021). Its genome has been termed "a genome in upheaval" due to the presence of multiple partial duplicates, gene fragments and pseudogenes (Zhang et al. 2021a). It was postulated that this rampant gene duplication, likely retrotransposon-mediated, is random and thus neutral or even maladaptive. But if the presence of a duplicated gene confers an increase in fitness, that gene will be fixed in the genome (Qian \& 
Zhang 2014). But why would multiple HSP gene copies be fixed in the UWO241 genome, and what would be the fitness advantage? HSPs in $C$. reinhardtii have been studied mostly for their role during stress responses (reviewed in Nordhues et al., 2010) but do they have an equivalent role in UWO241, an obligate psychrophile released from the challenges of a variable environment?

Detailed RNA-Seq analysis revealed that UWO241 induced the expression of some, but not all HSPs, when exposed to heat stress, regardless of the initial culturing temperature (Figure 8). This response was particularly strong for sHSP genes, and most of the HSP22A homologs were strongly upregulated by exposure to heat. The strong heat-induction of sHSP transcripts has been shown before in UWO241 under short-term heat stress (Possmayer et al. 2011), as well as in C. reinhardtii and other algae (Mühlhaus et al. 2011; Kobayashi et al. 2014; Uji, Gondaira, Fukuda, Mizuta \& Saga 2019; Liang et al. 2020). Curiously, UWO241 failed to accumulate increased protein amounts when challenged with heat stress, despite increased HSP transcript levels (Figure 7).

In a direct comparison with C. reinhardtii, we showed that UWO241 accumulates significantly higher protein amounts of major HSPs (HSP70A, HSP90A, CPN60A) under a range of steady-state growth temperatures in the absence of heat stress (Figure 9). Furthermore, we also observed high HSP levels in C. reinhardtii acclimated to $10^{\circ} \mathrm{C}$ (Figure 10). Cold induction of HSP expression has been previously observed in $C$. reinhardtii (Maikova, Zalutskaya, Lapina \& Ermilova 2016) and land plants (Renaut, Hausman \& Wisniewski 2006; Timperio, Egidi \& Zolla 2008), suggesting a role of chaperones during low-temperature growth. Unlike UWO241, C. reinhardtii cultured at $10^{\circ} \mathrm{C}$ retained the ability to induce further accumulation of most HSPs, including HSF1, when heat stressed despite having high levels of HSPs during steady-state growth (Figure 11). Thus, while high levels of HSPs are common between the two species at low temperature, only the mesophile could significantly increase HSP amounts when challenged with heat.

Whether constitutively high HSP levels confer resistance to heat is still a matter of debate. Thermotolerance in HSP over-expressors in plants, yeast and bacteria (Fragkostefanakis, Röth, Schleiff \& Scharf 2015; Santhanagopalan, Basha, Ballard, Bopp \& Vierling 2015) is often limited to a narrow range of conditions or a specific developmental stage (Fragkostefanakis et al. 2015; Waters \& Vierling 2020). Considering the increased evidence for broader roles of chaperones in cellular protein homeostasis (Lindquist \& Craig 1988; Vierling 2003; Wang et al. 2004; Gupta et al. 2010; Park \& Seo 2015), it appears that the ability of an organism to tightly regulate its central defense network plays a more prominent role in thermotolerance rather than the amount of chaperone proteins themselves. This certainly appears to be the case in UWO241, which cannot survive moderate temperatures (Figure 4a) despite constitutively accumulating high quantities of HSPs (Figure 9). Similarly, increased levels of HSPs in cold-grown C. reinhardtii did not confer greater survival under prolonged heat stress when compared to those grown at $28^{\circ} \mathrm{C}$ (Figure $4 \mathrm{~b}$ ). The significance of high HSP expression but not protein accumulation during heat stress is currently not clear. UWO241 does not experience temperature fluctuations in its natural environment, but inducible HSP expression could be a remnant of its distant past before its arrival in Lake Bonney. We do not know the evolutionary history of UWO241, but it is closely related to the marine species Chlamydomonas parkeae (Possmayer et al.2016), indicating an ancestral lifestyle in a variable environment where stress-induced protective pathways would be beneficial.

We propose that the constitutively high accumulation of HSPs in UWO241 plays an important role in protein quality control and ensures a robust capacity for protein folding at low temperatures, rather than protection from heat stress. Protein synthesis and the folding of nascent proteins are temperature-sensitive cellular processes (Hebraud, Dubois, Potier \& Labadie 1994; Phadtare 2004; Piette, Struvay \& Feller 2011; Rosa, Roberts \& Rodrigues 2017), and it has been suggested that the involvement of molecular chaperones is a crucial component of cold adaptation in psychrophilic bacteria (Piette et al. 2011; Feller 2013). We propose a similar role for HSPs in UWO241. One of the main differences between the primary metabolomes of UWO241 and C. reinhardtii were that $10^{\circ} \mathrm{C}$-grown C. reinhardtii showed high levels of amino acids, but UWO241 did not, at any growth temperature (Figure 3b, Table 1). Amino acid accumulation could be a protective cold stress response, or the consequence of decreased efficiency of protein synthesis at low 
temperatures in C. reinhardtii (Valledor, Furuhashi, Hanak \& Weckwerth 2013). The lack of a large free amino acid pool in UWO241 may indicate an efficient protein synthesis machinery that is not negatively affected by low temperatures.

Zhang et al . (2021) proposed that HSDs in the UWO241 genome aid in survival at extreme environments by contributing increased protein amounts via gene dosage (Kondrashov 2012; Qian \& Zhang 2014). Indeed, UWO241 was shown to have increased protein accumulation of photosynthetic ferredoxin (PETF) when compared to C. reinhardtii . Unlike other green algae, PETF in UWO241 is encoded by two near identical genes (Fd-1A and Fd-1B) (Cvetkovska et al. 2018). The increased PETF protein levels may contribute to the higher capacity for photosynthetic electron transport and maintenance of photostasis in UWO241 (Szyszka, Ivanov \& Hüner 2007; Szyszka-Mroz et al. 2019; Kalra et al. 2020). We propose that the expansion and duplicate-gene retention of the HSP gene family in UWO241 confers an adaptive advantage for life in the cold by increasing the capacity for protein folding at low temperatures.

\section{A constitutive stress response is a key psychrophilic adaptation.}

This study reveals novel insights into psychrophilic adaptation in the green alga UWO241 and potential roles of molecular chaperones and stress metabolism during cold adaptation and heat stress. In this work we showed that many molecular and metabolic signatures commonly used as stress markers in mesophiles (HSPs, carbohydrates, antioxidants) are constitutively accumulated at high levels in UWO241 grown at $4^{\circ} \mathrm{C}$. We propose that this is an adaptive advantage to life at extreme conditions, where a permanent exposure to extreme conditions has geared psychrophilic metabolism towards a permanent "stress state". What UWO241 appears to be lacking is the ability to fine-tune the regulation of this network, particularly the accumulation of HSPs, upon exposure to subsequent heat stress. For instance, in our work we did not detect up-regulation in HSF1 transcript, possibly due to the transient nature of its accumulation (Schmollinger et al. 2013), low protein levels, or low antibody specificity (data not shown). HSF1 has been shown to regulate HSP levels both during heat stress (Schmollinger et al. 2013) and cold stress (Maikova et al. 2016) in C. reinhardtii, but it is not clear whether a similar mechanism operates in UWO241. A more detailed analysis, including expression and protein accumulation of HSF1 using UWO241-specific antibodies is needed.

Our work adds to a growing body of research on how heat stress affects psychrophilic algae (Hwang, Jung \& Jin 2008; Chong, Chu, Othman \& Phang 2011; Possmayer et al. 2011; Boo et al. 2013; Suet al. 2016; Barati, Lim, Gan, Poong \& Phang 2018; Poonget al. 2018), a topic that is particularly relevant given recent trends in climate change. The Antarctic continent is one of the most rapidly warming locations on Earth (Chapman \& Walsh 2007). Studying the stress networks in psychrophilic algae will provide much needed insight into how these organisms adapt to their extreme environment and whether they are able to respond to temperature stress similarly to their mesophilic relatives.

Acknowledgments: The authors thank Dr. M. Schroda for the kind gift of HSP60A and HSP90C antibodies. We are grateful to Dr. Marc Possmayer for his assistance in algal culturing and RNA extraction.

Author contributions: MC, DRS and NPAH conceptualized the work and designed the experiments. MC wrote the initial draft, performed all cell death assays, microscopy, metabolomics experiments, UWO241 genomic screening and immunoblotting experiments in cooperation with BSM and NM. XZ performed global transcriptomic analysis. GV and SB performed HSP expression analysis and genomic screening of selected species. All authors contributed towards manuscript preparation and editing.

\section{Supplemental data:}

The following materials are available as supplemental data.

Supplemental datasets S1 and S2 : Relative abundance of all identified metabolites in C. reinhardtii and UWO241 grown at different steady-state temperatures and heat stress.

Supplemental dataset S3: A summary of the differentially expressed genes (DEGs) in steady-state grown UWO241. 
Supplemental dataset S4 : Summary of the differentially expressed genes (DEGs) in UWO241 grown at grown at $4^{\circ} \mathrm{C}, 10^{\circ} \mathrm{C}$ and $15^{\circ} \mathrm{C}$ and exposed heat stress $\left(24^{\circ} \mathrm{C}\right)$ for 6 hours.

Supplemental dataset S5 : KEGG analysis of the pathways significantly up- or down-regulated pathways in heat-shocked UWO241.

Supplemental dataset S6 : The Heat Shock Protein (HSP) gene family in chlorophyte, including a summary of the characteristics of the predicted HSPs in UWO241 and their expression profiles under steady state and heat stress.

Supplemental Figure S1. Light microscopy images of Chlamydomonas cells stained with 0.5\% Evans Blue.

Supplementary Figure S2. Chlorophyll loss in UWO241 and C. reinhardtii acclimated to different growth temperatures and exposed to non-permissive conditions $\left(24^{\circ} \mathrm{C}\right.$ and $\left.42^{\circ} \mathrm{C}\right)$.

Supplementary Figure S3. Light microscope images of C.reinhardtii acclimated to different steady state temperatures $\left(10^{\circ} \mathrm{C}, 28^{\circ} \mathrm{C}, 37^{\circ} \mathrm{C}\right)$ and exposed to non-permissive temperature $\left(42^{\circ} \mathrm{C}\right)$

Supplementary Figure S4. Cladograms representing phylogenetic relationships of the HSP genes in UWO241.

Supplementary Figure S5: A full protein alignment of the key domains in the cytosolic HSP70A proteins present in the UWO241 genome.

Supplementary Figure S6: Representative western blots showing the accumulation of HSPs in cultures of UWO241 and C. reinhardtiiat different steady-state temperatures.

\section{FIGURE TITLES:}

Figure 1: The maximal growth rate of exponentially growing algal cultures at various temperatures. (a) Chlamydomonas sp. UWO241 (b) Chlamydomonasreinhardtii. Data are the means \pm SD of at least six biological replicates.

Figure 2: Principal component analysis (PCA) of the primary metabolome of the two Chlamydomonas species acclimated to different steady-state temperatures. C. reinhardtii was grown at $10^{\circ} \mathrm{C}$ (magenta; $\mathrm{CR}_{-}-$ 10 ), $15^{\circ} \mathrm{C}$ (orange; $\mathrm{CR}_{-15}$ ), and $28^{\circ} \mathrm{C}$ (red; CR_28). UWO241 was grown at $4^{\circ} \mathrm{C}$ (cyan; UWO241_04), $10^{\circ} \mathrm{C}$ (blue; UWO241_10) and $15^{\circ} \mathrm{C}$ (green; UWO241_15). The analysis includes all 771 quantified metabolites separated along the first two principal components that explained the largest degree of variation in the datasets, and the $95 \%$ confidence interval for each treatment.

Figure 3. Differences in the primary metabolome of C. reinhardtii and UWO241, acclimated at different steady-state temperatures. (a ) Heat map showing the relative changes in metabolite abundances between growth temperatures in the two algal species. Only metabolites which are significantly different are shown (392 metabolites, ANOVA, $\mathrm{P}<0.01$ ). In each treatment, three biological replicates are represented using a color-based metabolite profile as indicated (red - increase in abundance; blue - decrease in abundance). Hierarchical clustering is based on Euclidean distances and Ward's linkage. (b ) Relative abundance of metabolites classified based on their chemical nature. Only metabolites which were positively identified based on their GC-MS spectra and retention times were taken into consideration. In this analysis, the metabolite abundance corresponding to C. reinhardtii grown at $28^{\circ} \mathrm{C}$ was arbitrarily set to 1 and all other treatments were compared to this sample.

Figure 4. Kinetics of cell death in UWO241 (a) and C. reinhardtii (b) acclimated to different growth temperatures and exposed to non-permissive conditions $\left(24^{\circ} \mathrm{C}\right.$ and $42^{\circ} \mathrm{C}$, respectively). Cell death was estimated as a percentage of algal cells stained with $0.5 \%$ Evans Blue that accumulates in cells with damaged membranes. Algal cells treated with $1 \% \mathrm{v} / \mathrm{v}$ chloroform were taken as a positive control and used to calculate $100 \%$ cell death. Data are means \pm SD of at least three independent experiments and analyzed by two-way ANOVA followed by Bonferroni post-test comparing each treatment with $4^{\circ} \mathrm{C}(\mathrm{UWO} 241)$ and $28^{\circ} \mathrm{C}$ (C. reinhardtii ). Statistical significance $(\mathrm{P}<0.01)$ is indicated as * $(\mathbf{c})$ Light microscope images of UWO241 acclimated to 
different steady state temperatures $\left(4^{\circ} \mathrm{C}, 10^{\circ} \mathrm{C}, 15^{\circ} \mathrm{C}\right)$ and exposed to non-permissive temperature $\left(24^{\circ} \mathrm{C}\right)$ for $24 \mathrm{~h}, 48 \mathrm{~h}$ and $72 \mathrm{~h}$. Algae are present as single cells or palmelloid colonies. Scale bar $=15 \mu \mathrm{m}$ (400x total magnification).

Figure 5. Principal component analysis (PCA) of the primary metabolome of UWO241 acclimated to different steady-state temperatures and subsequently exposed to non-permissive temperature for 6 hours. UWO241 was grown at $4^{\circ} \mathrm{C}$ (blue, UWO241_4) and exposed to $24^{\circ} \mathrm{C}$ (yellow, UWO241_4_HS); grown at $10^{\circ} \mathrm{C}$ (cyan; UWO241_10) and exposed to $24^{\circ} \mathrm{C}$ (orange, UWO241_10_HS); and grown at $15^{\circ} \mathrm{C}$ (green; UWO241_$15)$ and exposed to $24^{\circ} \mathrm{C}$ (red, UWO241_15_HS). The analysis includes all quantified metabolites separated along the first two principal components and the $95 \%$ confidence interval for each treatment.

Figure 6. Differences in the primary metabolome in UWO241 acclimated at different temperatures $\left(4^{\circ} \mathrm{C}\right.$, $\left.10^{\circ} \mathrm{C}, 15^{\circ} \mathrm{C}\right)$ and subsequently exposed to heat stress $\left(24^{\circ} \mathrm{C}\right)$ for 6 hours. (a) Heat map showing the relative changes in metabolite abundances between control samples at each steady-state growth temperature (C) and heat-treated samples (HS). Only metabolites that are significantly different are shown (314 metabolites, ANOVA, $\mathrm{P}<0.01)$. Three biological replicates are represented using a color-based metabolite profile as indicated (red - high abundance; blue - low abundance). Hierarchical clustering is based on Euclidean distances and Ward's linkage (b ) Relative abundance of metabolites classified based on their chemical nature. Only metabolites which were positively identified based on their GC-MS spectra and retention times were taken into consideration. In this analysis, the metabolite abundance in algae grown at the three different steady state temperatures were arbitrarily set to 1 (black bars) and all the heat stress treatments were compared to the corresponding control sample (blue bars).

Figure 7: Venn diagram indicating intersection of significantly up- (a) and down-regulated (b) differentially expressed genes (DEGs) in UWO241 grown at $4^{\circ} \mathrm{C}, 10^{\circ} \mathrm{C}$ and $15^{\circ} \mathrm{C}$. In this case, gene expression in the $4^{\circ} \mathrm{C}$ grown UWO241 cultures were compared with $15^{\circ} \mathrm{C}$ (blue, on the left) and $10^{\circ} \mathrm{C}$ (red, on the right). The number above indicates the total number of up- or down-regulated DEGs in that treatment. Venn diagrams indicating the intersection of significantly(c) Up- and (d) Down-regulated transcripts in UWO241 grown at $4^{\circ} \mathrm{C}$ (blue), $10^{\circ} \mathrm{C}$ (red) and $15^{\circ} \mathrm{C}$ (green) and exposed to heat stress $\left(24^{\circ} \mathrm{C}\right.$ ) for 6 hours. The number besides the diagram indicates the total number of differentially expressed DEGs in that treatment. In all cases, DEGs have a Fold Change $>4$, p-value $<0.05$ in three biological replicates.

Figure 8: Expression of Heat Shock Protein genes in UWO241 grown at three different temperatures $\left(4^{\circ} \mathrm{C}\right.$ $10^{\circ} \mathrm{C}$ and $15^{\circ} \mathrm{C}$ ) and exposed to heat stress $\left(24^{\circ} \mathrm{C}\right)$ for 6 hours. The average FPKM values of gene expression in three biological replicates are represented using a color-based expression profile as indicated (white low abundance; red - high abundance). All genes encoding putative HSP genes in the UWO241 genome are shown. The genes with a significantly higher expression $(\mathrm{FC}>4, \mathrm{p}<0.05)$ when compared to the corresponding control treatment (e.g., $4^{\circ} \mathrm{C}$ control compared to $4^{\circ} \mathrm{C} 24^{\circ} \mathrm{C}$ heat stressed sample) are highlighted with a red asterisk $(*)$. Only genes that are significantly regulated in all three heat shock treatments are highlighted.

Figure 9: Densitometry analysis of the relative HSP abundance determined by Western blotting in cultures of UWO241 (blue) and C. reinhardtii (red) acclimated to different steady-state temperatures. The protein abundance in the $4^{\circ} \mathrm{C}$-grown UWO241 was used as the basis of comparison for the relative abundance of HSPs in the other samples. In all cases, the results are the mean of 3 replicates $( \pm \mathrm{SD})$.

Figure 10: HSPs in C. reinhardtii acclimated to a steady-state low temperatures $\left(10^{\circ} \mathrm{C}\right.$ and $\left.15^{\circ} \mathrm{C}\right)$ accumulate at comparable levels to those in cultures acclimated to $28^{\circ} \mathrm{C}$ and exposed to $42^{\circ} \mathrm{C}$ for 6 hours. The data shown reflect typical results of three biological replicates.

Figure 11: Accumulation of Heat Shock proteins in cultures of UWO241 and C. reinhardtii cultured under different temperature regimes until mid-log stage $\left(37^{\circ} \mathrm{C}, 28^{\circ} \mathrm{C}\right.$ and $10^{\circ} \mathrm{C}$ for C. reinhardtii $; 15^{\circ} \mathrm{C}, 10^{\circ} \mathrm{C}$ and $4^{\circ} \mathrm{C}$ for UWO241) and exposed to 6 hours of heat stress at $42^{\circ} \mathrm{C}$ for $C$. reinhardtii and $24^{\circ} \mathrm{C}$ for UWO241. Due to differences in the initial HSP amount between the two species, the immunoblots were exposed and imaged at different intensities in order to capture the change in HSP accumulation between the control and heat stressed samples. The data shown here reflect typical results of three biological replicates. It should be 
noted that HSF1 could not be detected at the protein level in UWO241.

Figure 12 : The psychrophilic alga UWO241 is adapted to life at low but very stable temperatures of 4- $6^{\circ} \mathrm{C}$ year-round in Lake Bonney, Antarctica. Its physiology at low temperature is characterized by efficient photosynthetic rates comparable to those of $\mathrm{C}$. reinhardtii at $25-35^{\circ} \mathrm{C}$. (Pocock et al, 2011) and an active energy metabolism characterized by increased accumulation of CBB and TCA cycle intermediates. This active central metabolism fuels a constitutive accumulation of metabolites and proteins important for life at low temperatures, including soluble sugars, antioxidants, polyamines and molecular chaperones that ensure efficient protein folding at low temperatures. We propose that this permanent metabolic stress state provides UWO241 with the ability to cope with its extreme environment, but it also might impede its ability to finely manipulate this metabolic and molecular network in order to cope with additional environmental stressors.

\section{REFERENCES}

Anders S., Pyl P.T. \& Huber W. (2015) HTSeq - a Python framework to work with high-throughput sequencing data. Bioinformatics31, 166-169.

Armenteros J.J.A., Salvatore M., Emanuelsson O., Winther O., Heijne G. von, Elofsson A. \& Nielsen H. (2019) Detecting sequence signals in targeting peptides using deep learning. Life Science Alliance 2 .

Arriola M.B., Velmurugan N., Zhang Y., Plunkett M.H., Hondzo H. \& Barney B.M. (2018) Genome sequences of Chlorella sorokiniana UTEX 1602 and Micractinium conductrix SAG 241.80: implications to maltose excretion by a green alga. The Plant Journal 93, 566-586.

Barati B., Lim P.-E., Gan S.-Y., Poong S.-W. \& Phang S.-M. (2018) Gene expression profile of marine Chlorella strains from different latitudes: stress and recovery under elevated temperatures. Journal of Applied Phycology 30 , 3121-3130.

Blanc G., Agarkova I., Grimwood J., Kuo A., Brueggeman A., Dunigan D.D., .. Van Etten J.L. (2012) The genome of the polar eukaryotic microalga Coccomyxa subellipsoidea reveals traits of cold adaptation. Genome Biology 13 , R39.

Boo S.Y., Wong C.M.V.L., Rodrigues K.F., Najimudin N., Murad A.M.A. \& Mahadi N.M. (2013) Thermal stress responses in Antarctic yeast, Glaciozyma antarctica PI12, characterized by real-time quantitative PCR.Polar Biology 36 , 381-389.

Borowitzka M.A. (2018) The 'stress' concept in microalgal biology-homeostasis, acclimation and adaptation. Journal of Applied Phycology 30 , 2815-2825.

Caspeta L., Chen Y., Ghiaci P., Feizi A., Buskov S., Hallström B.M., .. Nielsen J. (2014) Altered sterol composition renders yeast thermotolerant. Science 346 , 75-78.

Chang C.Y.-Y., Bräutigam K., Hüner N.P.A. \& Ensminger I. (2021) Champions of winter survival: cold acclimation and molecular regulation of cold hardiness in evergreen conifers. New Phytologist229 ,675-691.

Chapman W.L. \& Walsh J.E. (2007) A Synthesis of Antarctic Temperatures.Journal of Climate 20 , 40964117 .

Chen D., Shao Q., Yin L., Younis A. \& Zheng B. (2019) Polyamine Function in Plants: Metabolism, Regulation on Development, and Roles in Abiotic Stress Responses. Frontiers in Plant Science 9.

Chong G.-L., Chu W.-L., Othman R.Y. \& Phang S.-M. (2011) Differential gene expression of an Antarctic Chlorella in response to temperature stress. Polar Biology 34,637-645.

Chong J., Soufan O., Li C., Caraus I., Li S., Bourque G., .. Xia J. (2018) MetaboAnalyst 4.0: towards more transparent and integrative metabolomics analysis. Nucleic Acids Research 46 , W486-W494.

Chrismas N.A.M., Anesio A.M. \& Sánchez-Baracaldo P. (2015) Multiple adaptations to polar and alpine environments within cyanobacteria: a phylogenomic and Bayesian approach. Frontiers in Microbiology 6 . 
Cook G., Teufel A., Kalra I., Li W., Wang X., Priscu J. \& Morgan-Kiss R. (2019) The Antarctic psychrophiles Chlamydomonas spp. UWO241 and ICE-MDV exhibit differential restructuring of photosystem I in response to iron. Photosynthesis Research 141, 209-228.

Cvetkovska M., Hüner N.P.A. \& Smith D.R. (2017) Chilling out: the evolution and diversification of psychrophilic algae with a focus on Chlamydomonadales. Polar Biology 40 , 1169-1184.

Cvetkovska M., Szyszka-Mroz B., Possmayer M., Pittock P., Lajoie G., Smith D.R. \& Hüner N.P.A. (2018) Characterization of photosynthetic ferredoxin from the Antarctic alga Chlamydomonas sp. UWO241 reveals novel features of cold adaptation. New Phytologist219, 588-604.

De Maayer P., Anderson D., Cary C. \& Cowan D.A. (2014) Some like it cold: understanding the survival strategies of psychrophiles. EMBO Reports 15, 508-517.

Debolt S., Melino V. \& Ford C.M. (2007) Ascorbate as a Biosynthetic Precursor in Plants. Annals of Botany $99,3-8$.

Demmig-Adams B., Garab G., Adams III W., \& Govindjee eds. (2014)Non-Photochemical Quenching and Energy Dissipation in Plants, Algae and Cyanobacteria . Springer Netherlands, Dordrecht.

Dolhi J.M., Maxwell D.P. \& Morgan-Kiss R.M. (2013) Review: the Antarctic Chlamydomonas raudensis: an emerging model for cold adaptation of photosynthesis. Extremophiles 17, 711-722.

Dreyer A. \& Dietz K.-J. (2018) Reactive Oxygen Species and the Redox-Regulatory Network in Cold Stress Acclimation. Antioxidants7 .

Feller G. (2013) Psychrophilic Enzymes: From Folding to Function and Biotechnology. Scientifica 2013 , $1-28$.

Fiehn O., Wohlgemuth G. \& Scholz M. (2005) Setup and Annotation of Metabolomic Experiments by Integrating Biological and Mass Spectrometric Metadata. In Data Integration in the Life Sciences . Lecture Notes in Computer Science, pp. 224-239. Springer, Berlin, Heidelberg.

Fiehn O., Wohlgemuth G., Scholz M., Kind T., Lee D.Y., Lu Y., ... Nikolau B. (2008) Quality control for plant metabolomics: reporting MSI-compliant studies. The Plant Journal 53 ,691-704.

Fragkostefanakis S., Röth S., Schleiff E. \& Scharf K.-D. (2015) Prospects of engineering thermotolerance in crops through modulation of heat stress transcription factor and heat shock protein networks. Plant, Cell $\mathscr{E}$ Environment 38, 1881-1895.

Fürtauer L., Weiszmann J., Weckwerth W. \& Nägele T. (2019) Dynamics of Plant Metabolism during Cold Acclimation. International Journal of Molecular Sciences 20 .

Ghahremani M., Ghanati F., Bernard F., Azad T., Gholami M. \& Safari M. Ornithine-induced increase of proline and polyamines contents in tobacco cells under salinity conditions. 6 .

Gill S.S. \& Tuteja N. (2010) Polyamines and abiotic stress tolerance in plants. Plant Signaling \& Behavior 5, 26-33.

Godinho C.P., Prata C.S., Pinto S.N., Cardoso C., Bandarra N.M., Fernandes F. \& Sá-Correia I. (2018) Pdr18 is involved in yeast response to acetic acid stress counteracting the decrease of plasma membrane ergosterol content and order. Scientific Reports 8 , 1-13.

Gray G.R. \& Heath D. (2005) A global reorganization of the metabolome in Arabidopsis during cold acclimation is revealed by metabolic fingerprinting. Physiologia Plantarum 124, 236-248.

Gupta S.C., Sharma A., Mishra M., Mishra R.K. \& Chowdhuri D.K. (2010) Heat shock proteins in toxicology: how close and how far? Life Sciences $\mathbf{8 6}, 377-384$. 
Guy C., Kaplan F., Kopka J., Selbig J. \& Hincha D.K. (2007) Metabolomics of temperature stress. Physiologia Plantarum 0 , 071124124159002-???

Hanschen E.R., Marriage T.N., Ferris P.J., Hamaji T., Toyoda A., Fujiyama A., .. Olson B.J.S.C. (2016) The Gonium pectorale genome demonstrates co-option of cell cycle regulation during the evolution of multicellularity. Nature Communications 7, 11370.

Hasanuzzaman M., Bhuyan M.H.M.B., Anee T.I., Parvin K., Nahar K., Mahmud J.A. \& Fujita M. (2019) Regulation of Ascorbate-Glutathione Pathway in Mitigating Oxidative Damage in Plants under Abiotic Stress. Antioxidants $\mathbf{8}$.

Hebraud M., Dubois E., Potier P. \& Labadie J. (1994) Effect of growth temperatures on the protein levels in a psychrotrophic bacterium, Pseudomonas fragi. Journal of Bacteriology 176 , 4017-4024.

Hemme D., Veyel D., Mühlhaus T., Sommer F., Jüppner J., Unger A.-K., .. Schroda M. (2014) SystemsWide Analysis of Acclimation Responses to Long-Term Heat Stress and Recovery in the Photosynthetic Model Organism Chlamydomonas reinhardtii . The Plant Cell26 , 4270-4297.

Hirooka S., Hirose Y., Kanesaki Y., Higuchi S., Fujiwara T., Onuma R., .. Miyagishima S. (2017) Acidophilic green algal genome provides insights into adaptation to an acidic environment. Proceedings of the National Academy of Sciences .

Horton P., Park K.-J., Obayashi T., Fujita N., Harada H., Adams-Collier C.J. \& Nakai K. (2007) WoLF PSORT: protein localization predictor.Nucleic Acids Research 35, W585-W587.

Hüner N.P.A., Bode R., Dahal K., Busch F.A., Possmayer M., Szyszka B., .. Maxwell D.P. (2012) Shedding some light on cold acclimation, cold adaptation, and phenotypic plasticity. Botany 91 , 127-136.

Huner N.P.A., Öquist G. \& Sarhan F. (1998) Energy balance and acclimation to light and cold. Trends in Plant Science3 , 224-230.

Hwang Y., Jung G. \& Jin E. (2008) Transcriptome analysis of acclimatory responses to thermal stress in Antarctic algae. Biochemical and Biophysical Research Communications 367 , 635-641.

Janská A., Maršík P., Zelenková S. \& Ovesná J. (2010) Cold stress and acclimation - what is important for metabolic adjustment? Plant Biology $12,395-405$.

Jeffrey S.W. \& Humphrey G.F. (1975) New spectrophotometric equations for determining chlorophylls a, b, c1 and c2 in higher plants, algae and natural phytoplankton. Biochemie und Physiologie der Pflanzen167, 191-194.

Kalamaki M.S., Alexandrou D., Lazari D., Merkouropoulos G., Fotopoulos V., Pateraki I., .. Kanellis A.K. (2009a) Over-expression of a tomato N-acetyl-L-glutamate synthase gene (SINAGS1) in Arabidopsis thaliana results in high ornithine levels and increased tolerance in salt and drought stresses. Journal of Experimental Botany 60 , 1859-1871.

Kalamaki M.S., Merkouropoulos G. \& Kanellis A.K. (2009b) Can ornithine accumulation modulate abiotic stress tolerance in Arabidopsis? Plant Signaling 83 Behavior 4 , 1099-1101.

Kalra I., Wang X., Cvetkovska M., Jeong J., McHargue W., Zhang R., ... Morgan-Kiss R.M. (2020) Chlamydomonas sp. UWO 241 exhibits high cyclic electron flow and rewired metabolism under high salinity. Plant Physiology, pp.01280.2019.

Kaplan F., Kopka J., Sung D.Y., Zhao W., Popp M., Porat R. \& Guy C.L. (2007) Transcript and metabolite profiling during cold acclimation of Arabidopsis reveals an intricate relationship of cold-regulated gene expression with modifications in metabolite content. The Plant Journal 50 , 967-981.

Kennicutt M.C., Bromwich D., Liggett D., Njåstad B., Peck L., Rintoul S.R., .. Chown S.L. (2019) Sustained Antarctic Research: A 21st Century Imperative. One Earth 1, 95-113. 
Kim D., Langmead B. \& Salzberg S.L. (2015) HISAT: a fast spliced aligner with low memory requirements. Nature Methods 12, 357-360.

Kind T., Wohlgemuth G., Lee D.Y., Lu Y., Palazoglu M., Shahbaz S. \& Fiehn O. (2009) FiehnLib: Mass Spectral and Retention Index Libraries for Metabolomics Based on Quadrupole and Time-of-Flight Gas Chromatography/Mass Spectrometry. Analytical Chemistry81, 10038-10048.

Kobayashi Y., Harada N., Nishimura Y., Saito T., Nakamura M., Fujiwara T., .. Misumi O. (2014) Algae Sense Exact Temperatures: Small Heat Shock Proteins Are Expressed at the Survival Threshold Temperature in Cyanidioschyzon merolae and Chlamydomonas reinhardtii. Genome Biology and Evolution 6 , 2731-2740.

Kondrashov F.A. (2012) Gene duplication as a mechanism of genomic adaptation to a changing environment. Proceedings of the Royal Society B: Biological Sciences 279 , 5048-5057.

Légeret B., Schulz-Raffelt M., Nguyen H.M., Auroy P., Beisson F., Peltier G., .. Li-Beisson Y. (2016) Lipidomic and transcriptomic analyses of Chlamydomonas reinhardtii under heat stress unveil a direct route for the conversion of membrane lipids into storage lipids.Plant, Cell \& Environment 39 , 834-847.

Leya T. (2013) Snow Algae: Adaptation Strategies to Survive on Snow and Ice. In Polyextremophiles: Life Under Multiple Forms of Stress . Cellular Origin, Life in Extreme Habitats and Astrobiology, (eds J. Seckbach, A. Oren \& H. Stan-Lotter), pp. 401-423. Springer Netherlands, Dordrecht.

Liang M.-H., Jiang J.-G., Wang L. \& Zhu J. (2020) Transcriptomic insights into the heat stress response of Dunaliella bardawil.Enzyme and Microbial Technology 132 , 109436.

Lindquist S. \& Craig E. (1988) The heat-shock proteins.undefined .

Lu S., Wang J., Chitsaz F., Derbyshire M.K., Geer R.C., Gonzales N.R., .. Marchler-Bauer A. (2020) CDD/SPARCLE: the conserved domain database in 2020. Nucleic Acids Research 48, D265-D268.

Luo W., Friedman M.S., Shedden K., Hankenson K.D. \& Woolf P.J. (2009) GAGE: generally applicable gene set enrichment for pathway analysis. BMC Bioinformatics 10, 161.

Lyon B. \& Mock T. (2014) Polar Microalgae: New Approaches towards Understanding Adaptations to an Extreme and Changing Environment.Biology 3, 56-80.

Maikova A., Zalutskaya Z., Lapina T. \& Ermilova E. (2016) The HSP70 chaperone machines of Chlamydomonas are induced by cold stress. Journal of Plant Physiology 204, 85-91.

Margesin R. ed. (2008) Psychrophiles: from biodiversity to biotechnology . Springer, Berlin.

Minocha R., Majumdar R. \& Minocha S.C. (2014) Polyamines and abiotic stress in plants: a complex relationship1. Frontiers in Plant Science $\mathbf{5}$.

Mistry J., Chuguransky S., Williams L., Qureshi M., Salazar G.A., Sonnhammer E.L.L., .. Bateman A. (2021) Pfam: The protein families database in 2021. Nucleic Acids Research 49, D412-D419.

Morgan-Kiss R.M., Priscu J.C., Pocock T., Gudynaite-Savitch L. \& Huner N.P.A. (2006) Adaptation and Acclimation of Photosynthetic Microorganisms to Permanently Cold Environments. Microbiology and Molecular Biology Reviews $\mathbf{7 0}$, 222-252.

Morita R.Y. (1975) Psychrophilic bacteria. Bacteriological Reviews 39 , 144-167.

Muhlhaus T., Weiss J., Hemme D., Sommer F. \& Schroda M. (2011) Quantitative Shotgun Proteomics Using a Uniform 15N-Labeled Standard to Monitor Proteome Dynamics in Time Course Experiments Reveals New Insights into the Heat Stress Response of Chlamydomonas reinhardtii.Molecular \& Cellular Proteomics : MCP 10 .

Neale P.J. \& Priscu J.C. (1995) The Photosynthetic Apparatus of Phytoplankton from a Perennially IceCovered Antarctic Lake: Acclimation to an Extreme Shade Environment. Plant and Cell Physiology36 , 
$253-263$.

Nordhues A., Miller S.M., Muhlhaus T. \& Schroda M. (2010) Chapter two - New Insights into the Roles of Molecular Chaperones in Chlamydomonas and Volvox. In International Review of Cell and Molecular Biology . (ed K.W. Jeon), pp. 75-113. Academic Press.

Nowicka B. \& Kruk J. (2012) Plastoquinol is more active than $\alpha$-tocopherol in singlet oxygen scavenging during high light stress of Chlamydomonas reinhardtii. Biochimica et Biophysica Acta (BBA) - Bioenergetics $1817,389-394$.

Obryk M.K., Doran P.T., Hicks J.A., McKAY C.P. \& Priscu J.C. (2016) Modeling the thickness of perennial ice covers on stratified lakes of the Taylor Valley, Antarctica. Journal of Glaciology 62 , 825-834.

Öquist G. \& Huner N.P.A. (2003) Photosynthesis of Overwintering Evergreen Plants. Annual Review of Plant Biology $54,329-355$.

Park C.-J. \& Seo Y.-S. (2015) Heat Shock Proteins: A Review of the Molecular Chaperones for Plant Immunity. The Plant Pathology Journal 31, 323-333.

Pertea M., Kim D., Pertea G.M., Leek J.T. \& Salzberg S.L. (2016) Transcript-level expression analysis of RNA-seq experiments with HISAT, StringTie and Ballgown. Nature Protocols 11, 1650-1667.

Phadtare S. (2004) Recent developments in bacterial cold-shock response. Current Issues in Molecular Biology $6,125-136$.

Piette F., Struvay C. \& Feller G. (2011) The protein folding challenge in psychrophiles: facts and current issues. Environmental Microbiology 13, 1924-1933.

Pocock T., Vetterli A. \& Falk S. (2011) Evidence for phenotypic plasticity in the Antarctic extremophile Chlamydomonas raudensis Ettl. UWO 241. Journal of Experimental Botany 62 , 1169-1177.

Polle J.E.W., Barry K., Cushman J., Schmutz J., Tran D., Hathwaik L.T., .. Magnuson J. (2017) Draft Nuclear Genome Sequence of the Halophilic and Beta-Carotene-Accumulating Green Alga Dunaliella salina Strain CCAP19/18. Genome Announcements 5 .

Poong S.-W., Lee K.-K., Lim P.-E., Pai T.-W., Wong C.-Y., Phang S.-M., .. Liu C.-C. (2018) RNASeq-mediated transcriptomic analysis of heat stress response in a polar Chlorella sp. (Trebouxiophyceae, Chlorophyta). Journal of Applied Phycology 30 , 3103-3119.

Possmayer M., Berardi G., Beall B.F.N., Trick C.G., Hüner N.P.A. \& Maxwell D.P. (2011) PLASTICITY OF THE PSYCHROPHILIC GREEN ALGA CHLAMYDOMONAS RAUDENSIS (UWO 241) (CHLOROPHYTA) TO SUPRAOPTIMAL TEMPERATURE STRESS1: HEAT STRESS IN A PSYCHROPHILIC GREEN ALGA.Journal of Phycology 47 , 1098-1109.

Possmayer M., Gupta R.K., Szyszka-Mroz B., Maxwell D.P., Lachance M., Huner N.P.A. \& Smith D.R. (2016) Resolving the phylogenetic relationship between Chlamydomonas sp. UWO 241 and Chlamydomonas raudensis sag 49.72 (Chlorophyceae) with nuclear and plastid DNA sequences. Journal of Phycology52, $305-310$.

Price M.N., Dehal P.S. \& Arkin A.P. (2010) FastTree 2 - Approximately Maximum-Likelihood Trees for Large Alignments. PLOS ONE5, e9490.

Prochnik S.E., Umen J., Nedelcu A.M., Hallmann A., Miller S.M., Nishii I., . . Rokhsar D.S. (2010) Genomic analysis of organismal complexity in the multicellular green alga Volvox carteri. Science (New York, N.Y.) 329 , 223-226.

Qian W. \& Zhang J. (2014) Genomic evidence for adaptation by gene duplication. Genome Research 24, 1356-1362. 
Renaut J., Hausman J.-F. \& Wisniewski M.E. (2006) Proteomics and low-temperature studies: bridging the gap between gene expression and metabolism. Physiologia Plantarum 126 , 97-109.

Ritossa F. (1962) A new puffing pattern induced by temperature shock and DNP in drosophila. Experientia $18,571-573$.

Robinson M.D., McCarthy D.J. \& Smyth G.K. (2010) edgeR: a Bioconductor package for differential expression analysis of digital gene expression data. Bioinformatics 26 , 139-140.

Rosa M., Roberts C.J. \& Rodrigues M.A. (2017) Connecting high-temperature and low-temperature protein stability and aggregation.PLOS ONE $\mathbf{1 2}$, e0176748.

Roser D.J., Melick D.R., Ling H.U. \& Seppelt R.D. (1992) Polyol and sugar content of terrestrial plants from continental Antarctica.Antarctic Science 4, 413-420.

Santhanagopalan I., Basha E., Ballard K.N., Bopp N.E. \& Vierling E. (2015) Model Chaperones: Small Heat Shock Proteins from Plants. In The Big Book on Small Heat Shock Proteins . Heat Shock Proteins, (eds R.M. Tanguay \& L.E. Hightower), pp. 119-153. Springer International Publishing, Cham.

Schmollinger S., Schulz-Raffelt M., Strenkert D., Veyel D., Vallon O. \& Schroda M. (2013) Dissecting the Heat Stress Response in Chlamydomonas by Pharmaceutical and RNAi Approaches Reveals Conserved and Novel Aspects. Molecular Plant 6 , 1795-1813.

Schroda M., Hemme D. \& Muhlhaus T. (2015) The Chlamydomonas heat stress response. The Plant Journal 82, 466-480.

Schroda M. \& Vallon O. (2009) Chapter 19 - Chaperones and Proteases. In The Chlamydomonas Sourcebook (Second Edition) . (eds E.H. Harris, D.B. Stern \& G.B. Witman), pp. 671-729. Academic Press, London.

Siddiqui K.S., Williams T.J., Wilkins D., Yau S., Allen M.A., Brown M.V., .. Cavicchioli R. (2013) Psychrophiles. Annual Review of Earth and Planetary Sciences 41, 87-115.

Sievers F., Wilm A., Dineen D., Gibson T.J., Karplus K., Li W., .. Higgins D.G. (2011) Fast, scalable generation of high-quality protein multiple sequence alignments using Clustal Omega. Molecular Systems Biology 7, 539 .

Sirikhachornkit A., Shin J.W., Baroli I. \& Niyogi K.K. (2009) Replacement of $\alpha$-Tocopherol by $\beta$-Tocopherol Enhances Resistance to Photooxidative Stress in a Xanthophyll-Deficient Strain of Chlamydomonas reinhardtii. Eukaryotic Cell 8, 1648-1657.

Small I., Peeters N., Legeai F. \& Lurin C. (2004) Predotar: A tool for rapidly screening proteomes for N-terminal targeting sequences.PROTEOMICS 4, 1581-1590.

Sperschneider J., Catanzariti A.-M., DeBoer K., Petre B., Gardiner D.M., Singh K.B., .. Taylor J.M. (2017) LOCALIZER: subcellular localization prediction of both plant and effector proteins in the plant cell. Scientific Reports $\mathbf{7}, 44598$.

Spigel R.H., Priscu J.C., Obryk M.K., Stone W. \& Doran P.T. (2018) The physical limnology of a permanently ice-covered and chemically stratified Antarctic lake using high resolution spatial data from an autonomous underwater vehicle. Limnology and Oceanography63, 1234-1252.

Su Y., Jiang X., Wu W., Wang M., Hamid M.I., Xiang M. \& Liu X. (2016) Genomic, Transcriptomic, and Proteomic Analysis Provide Insights Into the Cold Adaptation Mechanism of the Obligate Psychrophilic Fungus Mrakia psychrophila . G3G̈amp;\#58; Genes|Genomes|Genetics 6 , 3603-3613.

Swan T.M. \& Watson K. (1998) Stress tolerance in a yeast sterol auxotroph: role of ergosterol, heat shock proteins and trehalose.FEMS Microbiology Letters 169, 191-197.

Szarka A., Tomasskovics B. \& Bánhegyi G. (2012) The Ascorbate-glutathione- $\alpha$-tocopherol Triad in Abiotic Stress Response.International Journal of Molecular Sciences 13 ,4458-4483. 
Szyszka B., Ivanov A.G. \& Hüner N.P.A. (2007) Psychrophily is associated with differential energy partitioning, photosystem stoichiometry and polypeptide phosphorylation in Chlamydomonas raudensis. Biochimica et Biophysica Acta (BBA) - Bioenergetics1767, 789-800.

Szyszka-Mroz B., Cvetkovska M., Ivanov A.G., Smith D.R., Possmayer M., Maxwell D.P. \& Hüner N.P.A. (2019) Cold-Adapted Protein Kinases and Thylakoid Remodeling Impact Energy Distribution in an Antarctic Psychrophile. Plant Physiology 180 , 1291-1309.

Szyszka-Mroz B., Pittock P., Ivanov A.G., Lajoie G. \& Hüner N.P.A. (2015) The Antarctic Psychrophile Chlamydomonas sp. UWO 241 Preferentially Phosphorylates a Photosystem I-Cytochrome b6/f Supercomplex. Plant Physiology $169,717-736$.

Taïbi K., Del Campo A.D., Vilagrosa A., Bellés J.M., López-Gresa M.P., López-Nicolás J.M. \& Mulet J.M. (2018) Distinctive physiological and molecular responses to cold stress among cold-tolerant and cold-sensitive Pinus halepensis seed sources. BMC Plant Biology 18, 236.

Tang E.P.Y. \& Vincent W.F. (1999) Strategies of thermal adaptation by high-latitude cyanobacteria. New Phytologist $142,315-323$.

Timperio A.M., Egidi M.G. \& Zolla L. (2008) Proteomics applied on plant abiotic stresses: Role of heat shock proteins (HSP). Journal of Proteomics 71, 391-411.

Trebst A., Depka B. \& Holländer-Czytko H. (2002) A specific role for tocopherol and of chemical singlet oxygen quenchers in the maintenance of photosystem II structure and function in Chlamydomonas reinhardtii.FEBS Letters $\mathbf{5 1 6}, 156-160$.

Tulha J., Lima A., Lucas C. \& Ferreira C. (2010) Saccharomyces cerevisiae glycerol/H+ symporter Stl1p is essential for cold/near-freeze and freeze stress adaptation. A simple recipe with high biotechnological potential is given. Microbial Cell Factories $\mathbf{9}$, 82.

Uji T., Gondaira Y., Fukuda S., Mizuta H. \& Saga N. (2019) Characterization and expression profiles of small heat shock proteins in the marine red alga Pyropia yezoensis. Cell Stress $\&$ Chaperones 24, 223-233.

Valledor L., Furuhashi T., Hanak A.-M. \& Weckwerth W. (2013) Systemic Cold Stress Adaptation of Chlamydomonas reinhardtii. Molecular \& Cellular Proteomics : MCP 12, 2032-2047.

Vanegas J.M., Contreras M.F., Faller R. \& Longo M.L. (2012) Role of Unsaturated Lipid and Ergosterol in Ethanol Tolerance of Model Yeast Biomembranes. Biophysical Journal 102 , 507-516.

Vierling E. (2003) The Roles of Heat Shock Proteins in Plants.Annual Review of Plant Physiology 42 , 579-620.

Wang W., Vinocur B., Shoseyov O. \& Altman A. (2004) Role of plant heat-shock proteins and molecular chaperones in the abiotic stress response. Trends in Plant Science $\mathbf{9}, 244-252$.

Wanner L.A. \& Junttila O. (1999) Cold-Induced Freezing Tolerance in Arabidopsis. Plant Physiology 120, 391-400.

Waters E.R. \& Vierling E. (2020) Plant small heat shock proteins - evolutionary and functional diversity. New Phytologist 227, 24-37.

Xavier J.C., Brandt A., Ropert-Coudert Y., Badhe R., Gutt J., Havermans C., .. S Sutherland W.J. (2016) Future Challenges in Southern Ocean Ecology Research. Frontiers in Marine Science $\mathbf{3}$.

Yamori W., Hikosaka K. \& Way D.A. (2014) Temperature response of photosynthesis in C3, C4, and CAM plants: temperature acclimation and temperature adaptation. Photosynthesis Research 119, 101-117.

Zhang X., Cvetkovska M., Morgan-Kiss R., Huner N.P.A. \& Smith D.R. (2021a) Draft genome sequence of the Antarctic green alga Chlamydomonas sp. UWO241. iScience 24, 102084. 
Zhang X., Hu Y. \& Smith D.R. (2021b) Protocol for HSDFinder: Identifying, annotating, categorizing, and visualizing duplicated genes in eukaryotic genomes. STAR Protocols 2, 100619.

Zhang Z., Qu C., Zhang K., He Y., Zhao X., Yang L., ... Miao J. (2020) Adaptation to Extreme Antarctic Environments Revealed by the Genome of a Sea Ice Green Alga. Current Biology 30, 3330-3341.e7.

\section{TABLES}

Table 1: The 20 metabolites that show the largest differences in abundance between the C. reinhardtii and UWO241 acclimated to different steady state temperatures. The metabolite abundance corresponding to C. reinhardtii grown at $28 \mathrm{degC}$ was arbitrarily set to 1 and all other treatments were compared it. The numbers represent FC as an average between three biological repeats, with (-) representing a decrease and a $(+)$ representing an increase in abundance. The values that are significantly different in comparison to the control sample are marked with * $(\mathrm{p}<0.01$, ANOVA, Tukey's post hoc test). The main pathways that each metabolite is involved in was designated using the KEGG database (not an exhaustive list)\#

\begin{tabular}{|c|c|c|c|c|}
\hline Metabolite & Class & KEGG Pathway & $\begin{array}{l}\text { C. reinhardtii } \\
15^{\circ} \mathrm{C}\end{array}$ & $\begin{array}{l}\text { C. reinhardtii } \\
\mathbf{1 0}^{\circ} \mathbf{C}\end{array}$ \\
\hline Glucose & Carbohydrate & cre00010; cre00030 & +1.06 & $+1.69 *$ \\
\hline$\alpha$-ketoglutarate & Carboxylic acid & cre00020; cre00053; cre01230 & -1.02 & +2.25 \\
\hline 3-phosphoglycerate & Carboxylic acid & cre00010; cre00030; cre01230; cre00523 & -1.18 & $+7.34^{*}$ \\
\hline Phosphoenolpyruvate & Carboxylic acid & cre00020; cre00010; cre00710; cre01230 & +1.57 & $+4.46^{*}$ \\
\hline Lactic acid & Carboxylic acid & cre00620; cre00010; cre00051 & $+6.94 *$ & $+70.16^{*}$ \\
\hline Galactinol & Sugar alcohol & cre00052 & $-4.69 *$ & $-2.11^{*}$ \\
\hline Mannitol & Sugar alcohol & cre00051 & -2.94 & +1.09 \\
\hline Ornithine & Amino acid & cre01230 & +2.85 & $+9.68^{*}$ \\
\hline Histidine & Amino acid & cre01230 & $+6.76^{*}$ & $+22.94^{*}$ \\
\hline Glutamine & Amino acid & cre01230; cre00230, cre00240; cre00910 & +4.61 & $+35.20 *$ \\
\hline Lysine & Amino acid & cre01230 & $+7.25^{*}$ & $+27.98 *$ \\
\hline Cysteine & Amino acid & cre01230; cre00920 & -2.04 & $+1.66^{*}$ \\
\hline Aspartic acid & Amino acid & cre01230; cre00710; cre00760 & +1.71 & $+2.29^{*}$ \\
\hline N-acetylglutamate & Amino acid (derivative) & cre00220 & $+4.13^{*}$ & $+20.62 *$ \\
\hline Thymidine & $\mathrm{N}$-containing & cre00240 & +1.21 & +2.03 \\
\hline Xanthine & N-containing & cre00230 & $+1.84^{*}$ & $+13.59 *$ \\
\hline Ergosterol & Lipid & cre00100 & +6.25 & $-18.11^{*}$ \\
\hline Linoleic acid & Fatty acid & cre01040 & $-1.89^{*}$ & $-8.60^{*}$ \\
\hline Dehydroascorbic acid & Antioxidant & cre00053; cre00480 & +3.25 & $+19.68^{*}$ \\
\hline Threonic acid & Sugar acid & cre00053 & $+7.34^{*}$ & $+201.97^{*}$ \\
\hline
\end{tabular}

\#KEGG Partways: cre00010 - Glycolysis/Glyconeogenesis; cre00020 - TCA cycle; cre00030 - Pentose phosphate pathway; cre00051 - Fructose and mannose metabolism; cre00052 - Galactose metabolism; cre00053 - Ascorbate and alderate metabolism; cre00100 - Steroid biosynthesis; cre01040 - Biosynthesis of unsaturated fatty acids; cre01230 - Biosynthesis of amino acids; cre00220 - Arginine biosynthesis; cre00230 Purine metabolism; cre00240 - Pyrimidine metabolism; cre00480 - Glutathione metabolism; cre00523 Glycerolipid metabolism; cre00710 - Carbon fixation in photosynthetic organisms; cre00760 - Nicotinate and nicotinamide metabolism; cre00620 - Pyruvate metabolism; cre00910 - Nitrogen metabolism; cre00920 - Sulfur metabolism

Table 2: The 20 metabolites that show the largest differences in abundance from UWO241 acclimated to different steady state temperatures and exposed to non-permissive temperature for 6 hours. The metabolite abundance corresponding to cultures grown at steady-state conditions was arbitrarily set to 1 and all other treatments were compared to the control sample. The numbers represent FC as an average between three biological repeats, with (-) representing a decrease and a (+) representing an increase in abundance. The 
values that are significantly different in comparison to the control sample are marked with * $(\mathrm{p}<0.01$, ANOVA, Tukey's post hoc test). The main pathways that each metabolite is involved in was designated using the KEGG database (not an exhaustive list)\#

\begin{tabular}{|c|c|c|}
\hline Metabolite & Class & KEGG Pathway \\
\hline Sucrose & Carbohydrate & cre00500 \\
\hline Ribose & Carbohydrate & cre00030 \\
\hline$\alpha$-ketoglutarate & Carboxylic acid & cre00020; cre00053; cre01230 \\
\hline Pyruvic acid & Carboxylic acid & cre00010; cre00020; cre00030; cre00710 cre00053; cre01230; cre00760 \\
\hline Fructose-1,6-bisphosphate & Sugar phosphate & cre00010; cre00030; cre00051 \\
\hline Glucose-6-phosphate & Sugar phosphate & cre00010; cre00030; cre00500 \\
\hline Mannitol & Sugar alcohol & cre00051 \\
\hline Glutamine & Amino acid & cre01230, cre00230; cre00240; cre00910 \\
\hline Lysine & Amino acid & cre01230 \\
\hline Histidine & Amino acid & cre01230 \\
\hline Aspartic acid & Amino acid & cre01230; cre00710; cre00760 \\
\hline Tryptophan & Amino acid & cre01230 \\
\hline Serotonin & Amino acid (derivative) & cre01230 \\
\hline Glycyl tyrosine & Amino acid (derivative) & cre01230 \\
\hline Adenosine & N-containing & cre00230 \\
\hline Inosine 5'-monophosphate & $\mathrm{N} / \mathrm{P}$-containing & cre00230 \\
\hline Oleic acid & Fatty acid & cre01040 \\
\hline Linolenic acid & Fatty acid & cre01040 \\
\hline Ergosterol & Lipid & cre00100 \\
\hline$\alpha$-tocopherol & Antioxidant & cre01110 \\
\hline
\end{tabular}

\#KEGG Partways: cre00010 - Glycolysis/Glyconeogenesis; cre00020 - TCA cycle; cre00030 - Pentose phosphate pathway; cre00051 - Fructose and mannose metabolism; cre00053 - Ascorbate and alderate metabolism; cre00100 - Steroid biosynthesis; cre00230 - Purine metabolism; cre00240 - Pyrimidine metabolism; cre00500 - Starch and sucrose metabolism; cre00710 - Carbon fixation in photosynthetic organisms; cre00760 - Nicotinate and nicotinamide metabolism; cre00910 - Nitrogen metabolism; cre01040 - Biosynthesis of unsaturated fatty acids; cre01110 - Biosynthesis of secondary metabolites; cre01230 Biosynthesis of amino acids

Table 3: KEGG analysis of the pathways significantly up-regulated $(-)$ or down-regulated (-) in heatshocked UWO241 $\left(4-24^{\circ} \mathrm{C} ; 10-24^{\circ} \mathrm{C} ; 15-24^{\circ} \mathrm{C}\right)$ as analyzed by Gage. Only pathways significantly enriched by DEGs are shown $(\mathrm{p}$-value $<0.05)$

\begin{tabular}{|c|c|c|c|}
\hline KEGG Pathway & $4-24^{\circ} \mathrm{C}$ & $10-24^{\circ} \mathrm{C}$ & $15-24^{\circ} \mathrm{C}$ \\
\hline cre00020 Citrate cycle (TCA cycle) & - & - & - \\
\hline cre00061 Fatty acid biosynthesis & & - & \\
\hline cre00190 Oxidative phosphorylation & - & - & \\
\hline cre00230 Purine metabolism & & - & - \\
\hline cre00240 Pyrimidine metabolism & - & - & - \\
\hline cre00270 Cysteine and methionine metabolism & - & - & - \\
\hline cre00400 Phenylalanine, tyrosine and tryptophan bios. & - & & - \\
\hline cre01100 Metabolic pathways & - & - & - \\
\hline cre01110 Biosynthesis of secondary metabolites & - & - & - \\
\hline cre01200 Carbon metabolism & & - & - \\
\hline cre01230 Biosynthesis of amino acids & - & - & - \\
\hline cre01240 Biosynthesis of cofactors & - & - & \\
\hline
\end{tabular}




\begin{tabular}{llll}
\hline KEGG Pathway & $\mathbf{4 - 2 4}^{\circ} \mathbf{C}$ & $\mathbf{1 0 - 2 4}^{\circ} \mathbf{C}$ & $\mathbf{1 5 - 2 4}^{\circ} \mathbf{C}$ \\
\hline cre03008 Ribosome biogenesis in eukaryotes & - & - & \\
cre03018 RNA degradation & - & & \\
cre03020 RNA polymerase & - & - & - \\
cre03030 DNA replication & & - & \\
cre04120 Ubiquitin mediated proteolysis & - & - \\
cre04141 Protein processing in endoplasmic reticulum & - & - & - \\
cre04144 Endocytosis & - & - & - \\
\hline
\end{tabular}

Table 4: The number of Heat Shock Proteins in various algal species. Species are ordered according to their evolutionary relationship to UWO241 (Possmayer et al. 2016; Zhang et al. 2020). The species with significantly more than the average number of HSPs in a particular class are highlighted with *. Algal species: Ceu, Chlamydomonas eustigma ; Dsa, Dunaliella salina ; Cre,Chlamydomonas reinhardtii ; Gpe, Gonium pectorale ; Vca, Volvox carteri ; Cso, Chlorella sorokiniana ; Csu, Coccomyxa subellipsoidea C-169

\begin{tabular}{llllllllll}
\hline & UWO241 & Ceu & ICE-L & Dsa & Cre & Gpe & Vca & Cso & Csu \\
\hline HSF TF & 1 & 2 & 1 & 1 & 2 & 1 & 2 & 1 & 1 \\
HSP100s/Clp & $\mathbf{1 2}^{*}$ & 9 & $\mathbf{1 2}^{*}$ & 8 & 8 & 9 & 11 & 7 & 6 \\
HSP90s & 3 & 4 & $\mathbf{6}^{*}$ & 4 & 3 & 3 & 3 & 3 & 3 \\
HSP70s & $\mathbf{1 6}^{*}$ & 8 & 10 & 8 & 9 & 10 & 10 & 9 & 9 \\
HSP60s & $\mathbf{6}^{*}$ & 4 & $\mathbf{6}^{*}$ & 3 & 4 & 4 & 3 & 3 & 3 \\
HSP40s (DnaJ-like) & 5 & 3 & 4 & 5 & 6 & 5 & 5 & 3 & 5 \\
sHSPs & 11 & 1 & $\mathbf{1 2}^{*}$ & $\mathbf{1 3}^{*}$ & 9 & 6 & 6 & 2 & 4 \\
Total & $\mathbf{5 4}$ & $\mathbf{3 1}$ & $\mathbf{5 1}$ & $\mathbf{4 2}$ & $\mathbf{4 1}$ & $\mathbf{3 8}$ & $\mathbf{4 0}$ & $\mathbf{2 8}$ & $\mathbf{3 1}$ \\
\hline
\end{tabular}

\section{Hosted file}

Heat_stress_combined_figures_FINAL_July_2021.pdf available at https://authorea.com/ users/403498/articles/530682-a-constitutive-stress-response-is-an-adaptation-to-lowtemperature-in-the-antarctic-green-alga-chlamydomonas-sp-uwo241 